\title{
Cell fusion*
}

Benjamin Podbilewicz ${ }^{1,2, \S}$

\section{${ }^{1}$ Department of Biology, Technion-Israel, Institute of Technology, Haifa 32000, Israel \\ ${ }^{2}$ Section on Membrane Biology, Laboratory of Cellular and Molecular Biophysics, NICHD, NIH, Bethesda MD 20892, USA}

\section{Table of Contents}

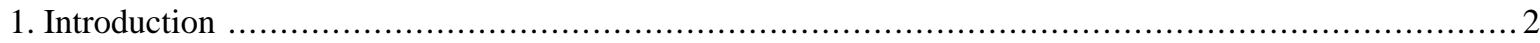

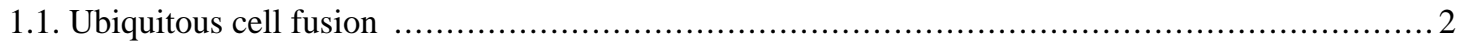

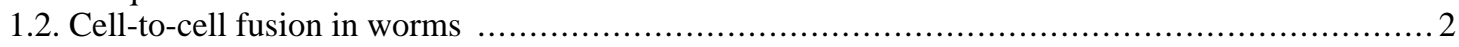

1.3. Humans and some nematodes have cellular skin but $C$. elegans has syncytia ....................... 3

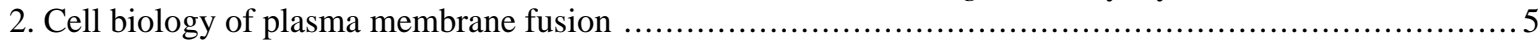

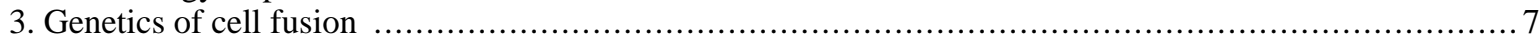

4. eff- 1 is necessary for most, but not all, cell fusion events in $C$. elegans .................................... 7

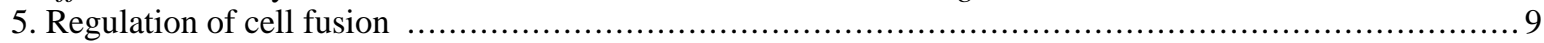

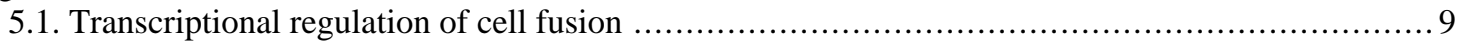

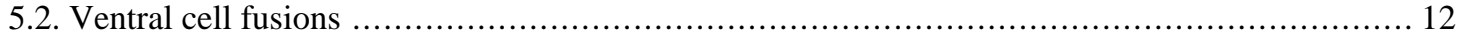

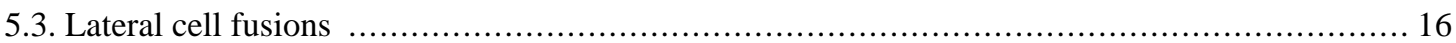

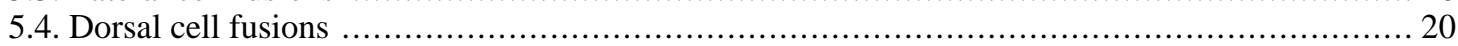

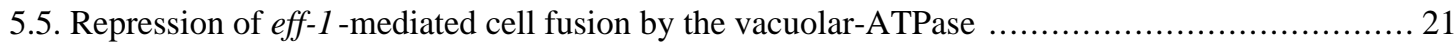

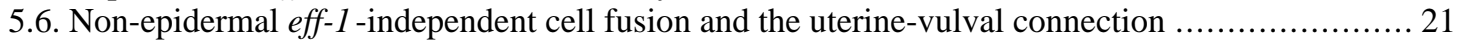

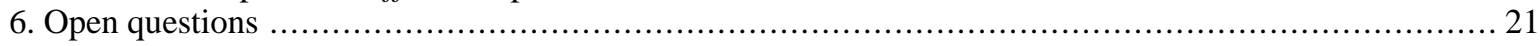

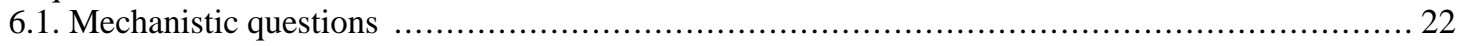

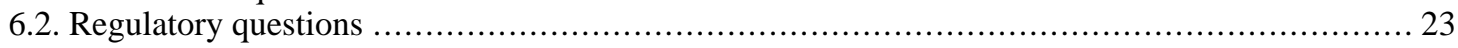

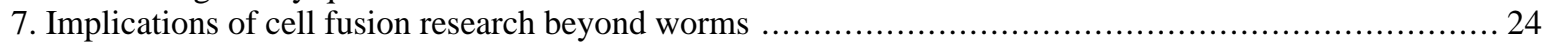

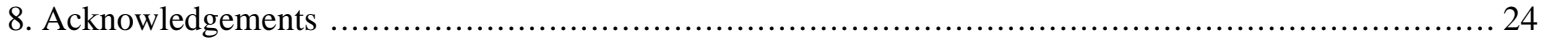

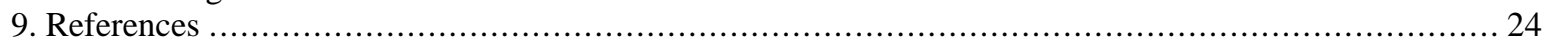

\begin{abstract}
Selective cell fusion is a natural part of development. It is found in sexually reproducing organisms that require fertilization to propagate and in muscles, placenta, bones, lens of the eye and stem cells. Cell fusion is particularly important in the development of $C$. elegans: in addition to 300 sperm and oocytes that fuse
\end{abstract}

*Edited by James M. Kramer and Donald G. Moerman. Last revised April 28, 2005. Published January 06, 2006. This chapter should be cited as: Podbilewicz, B. Cell fusion (January 06, 2006), WormBook, ed. The C. elegans Research Community, WormBook, doi/10.1895/wormbook. 1.52.1, http://www.wormbook.org.

Copyright: (C) 2006 Benjamin Podbilewicz. This is an open-access article distributed under the terms of the Creative Commons Attribution License, which permits unrestricted use, distribution, and reproduction in any medium, provided the original author and source are credited.

${ }^{\S}$ To whom correspondence should be addressed. E-mail: podbilew@tx.technion.ac.il 
during fertilization, 300 of the 1090 somatic cells born, fuse throughout development. Studies of cell fusion in C. elegans have shown that although different types of cells fuse, cell membrane merger is initiated through a common mechanism involving the action of one gene, eff-1. In worms with mutations that inactivate eff-1, almost none of the 300 somatic cells that normally fuse do so, but appear to differentiate, attach and behave in the same way as fusing cells. Such worms develop and survive but have numerous morphological, behavioral and fertility defects associated to cell fusion failure in the epidermis, pharynx, male tail, vulva and uterus. Cell fusion in embryonic dorsal epithelial cells has been analyzed in great detail by confocal microscopy using membrane fluorescent probes, apical junction markers and cytoplasmic aqueous fluorescent probes allowing the direct observation of membrane disappearance, pore expansion and cytoplasmic content mixing. The complete elimination of the membranes between two fusing cells takes about 30 min and involves vesiculation of the fusing membranes. Genetic and cell biological evidence indicates that eff-1 activity is both necessary and sufficient to fuse epithelial and myoepithelial cells in vivo. Based on electron microscopic analyses of intermediates of cell fusion in eff- 1 mutants, it appears that eff-1 is required for both initiation and expansion of fusion pores, similar to the fusogen of Influenza virus. While only one gene encoding a novel candidate component of the cell membrane fusion machinery has been found, the nematode's cell fusion program is under the control of many cell-specific transcriptional regulators. A large number of these conserved regulators prevent cell fusion by repressing eff-1 activity. For example, if either ceh-16/engrailed or the GATA factor EGL-18/ELT-5 is inactivated, the lateral epidermal cells that normally do not fuse in the embryo will fuse causing embryonic lethality. And if either the Hox protein lin-39/Deformed or its cofactor ceh-20/Extradenticle is inactivated, the ventral epidermal vulval precursor cells that normally do not fuse in the larvae will fuse and the hermaphrodite will have no vulva. In addition, there is evidence for coordinated and complex regulation of lin-39 in the ventral epidermis by Ras, Wnt, Rb/E2F, NuRD and lin-15 pathways. It appears that in many cells that normally do not fuse, specific transcription complexes repress eff-1 expression preventing cell fusion. ref-2 (REgulator of Fusion-2) encodes a Zn-finger protein that is required to generate ventral Pn.p cells and to keep them unfused both in males and hermaphrodites. ref-2 is necessary, but not sufficient, to maintain Pn.p cells unfused. This review shows that far from cell fusion being an unusual phenomenon, there is the clear prospect that animal cells in all tissues are intrinsically programmed to fuse, and are only prevented from fusing by transcriptional and post-transcriptional control mechanisms. There are three major questions that remain open for future research: (1) How does eff-1 fuse cells? (2) How do Ras, Wnt, Rb, NuRD, E2F, heterochronic and other pathways control cell fusion? (3) What are the implications of cell fusion beyond worms?

\section{Introduction}

\subsection{Ubiquitous cell fusion}

Cell fusion is found in many sexually reproducing organisms that require fertilization or mating to propagate (Heiman and Walter, 2000; Primakoff and Myles, 2002; Shur et al., 2004; Singson et al., 1998; Stein et al., 2004; Trueheart and Fink, 1989; Wassarman et al., 2001; Xu and Sternberg, 2003). Diverse organisms form multinucleate cells in organs such as muscles, placenta, bones, lens of the eye and stem cells, although most cells do not fuse during development. (Baroux et al., 2004; Chen and Olson, 2004 ; Cross et al., 1994; Hickey et al., 2002; Jee and Nolan, 1963; Kuszak et al., 1985; Terada et al., 2002; Xiang et al., 2002; Ying et al., 2002). In addition, cell invasive behaviors involve fusion between cells, such as viral induced cell fusion and anchor cell invasion and fusion in $C$. elegans (Earp et al., 2005; Newman et al., 1996; Sharma-Kishore et al., 1999). Little is known about the mechanisms of cell fusion. In C. elegans, some of the components of the machinery that brings about and regulates cell fusion have been identified. While many cell-specific transcriptional regulators of cell fusion have been characterized, to date, only one gene encoding a candidate component of the cell membrane fusion machinery has been identified. This chapter includes sections on transcriptional regulation of cell fusion and on a novel candidate cell fusion machinery gene.

\subsection{Cell-to-cell fusion in worms}

Over $30 \%$ of all somatic nuclei in C. elegans are contained within giant cells generated by cell fusion (Hedgecock and White, 1985; Podbilewicz and White, 1994; Sulston and Horvitz, 1977; Sulston et al., 1983; White, 1988; see Figure 1; Wormatlas, Epidermal morphogenesis, Male development and Vulval development). These cells are formed during embryonic and larval development in a genetically programmed process. Syncytiogenesis culminates in complex cellular structures, such as, myoepithelial cells in the pharynx and epithelial toroids (ring shape cells) in the uterus, vulva and male tail (Figure 1; Newman et al., 1996; Nguyen et al., 1999; Sharma-Kishore et al., 1999). For reviews on cell fusion in worms see (Podbilewicz, 2000; Podbilewicz and Chernomordik, 2005; 
Shemer and Podbilewicz, 2000; Shemer and Podbilewicz, 2003; Witze and Rothman, 2002). For sperm-egg fusion see chapters on Control of oocyte meiotic maturation and fertilization and Spermatogenesis.

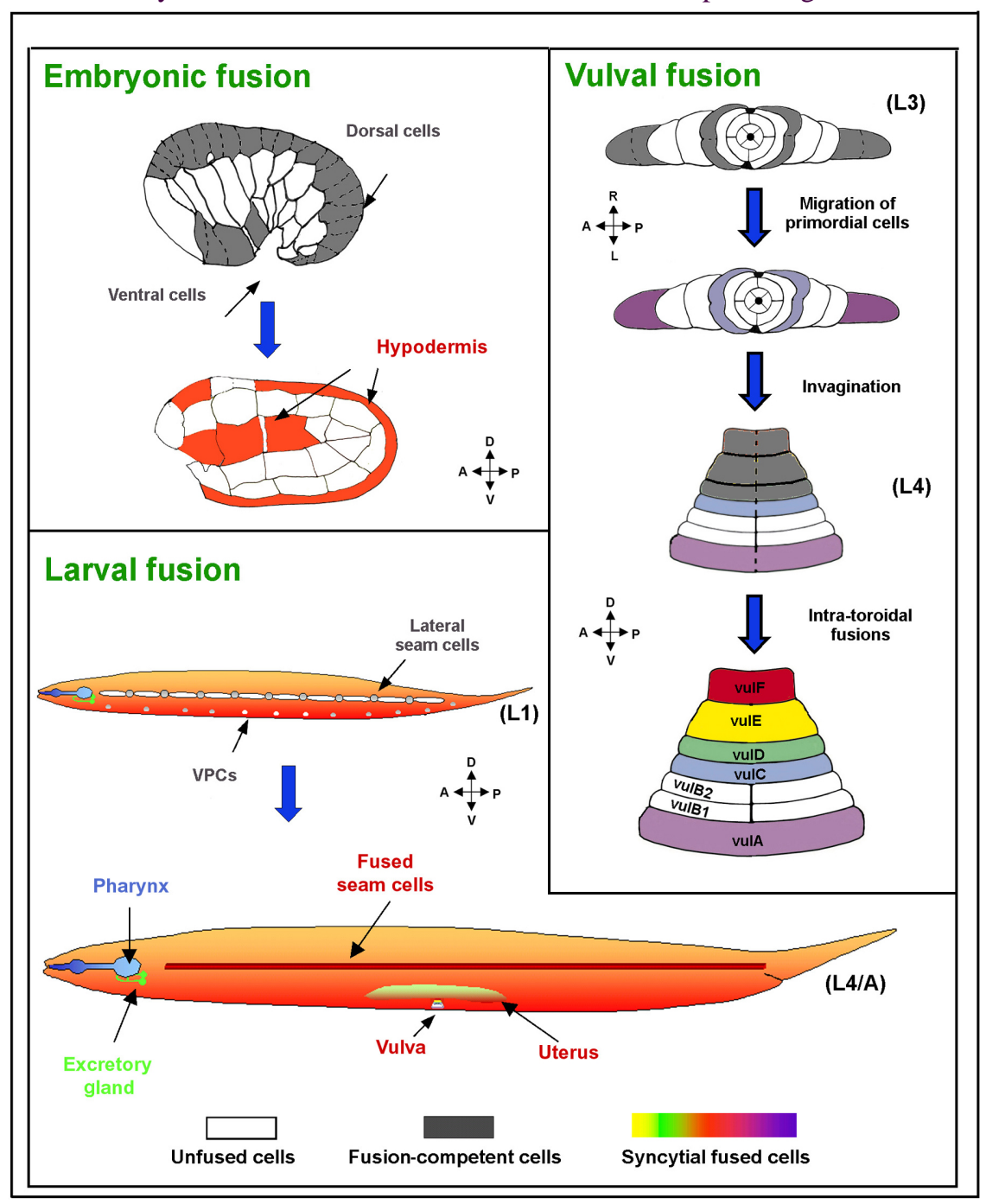

Figure 1. Cell fusion in C. elegans. Membranes of cells committed for fusion (gray color and dashed lines) fuse throughout development forming different syncytia (colored). White marks unfused cells. During embryonic elongation most of the dorsal cells, along with several ventral cells fuse to form the hypodermal syncytia (Podbilewicz and White, 1994). More nuclei join these syncytia during larval development as a consequence of fusion of part of the lateral hypodermal seam cells, as well as part of the ventral epidermal cells. The resulting epidermis is comprised of 8 syncytia containing 186 nuclei (not shown) and only 3 unfused cells (for details, see Wormatlas). Other organs, such as the pharynx, excretory gland, uterus and vulva also contain syncytia (Sulston and Horvitz, 1977; Sulston et al., 1983). During vulva organogenesis, cell fusion takes place between migrating cells (precursors of the vulA and vulC rings; violet and light blue, respectively), as well as between cells within the vulval rings (Sharma-Kishore et al., 1999). In total, 300 of 959 somatic nuclei in C. elegans are part of syncytia (Shemer and Podbilewicz, 2000). Reproduced from Shemer and Podbilewicz (2003), Copyright (2003), with permission from Wiley.

\subsection{Humans and some nematodes have cellular skin but $C$. elegans has syncytia}

The largest organ in worms and humans is the epidermis (hypodermis). In some marine nematodes and in vertebrates the skin and most other organs are cellular. However, in C. elegans and related nematodes the epidermis is composed of several distinct multinucleate cells (syncytia; Chitwood and Chitwood, 1974; Hedgecock and White, 1985; Podbilewicz and White, 1994; Sulston and Horvitz, 1977). These syncytia are generated by the fusion of mononucleate cells during development. The largest syncytium is hyp7 which is generated in the embryo during morphogenesis (Figure 1; Podbilewicz and White, 1994; Sulston et al., 1983). During larval development additional cells fuse with hyp7 (Podbilewicz and White, 1994; Yochem et al., 1998). Several cells in the ventral and lateral epidermis remain unfused, divide and generate ectodermal organs including sex-specific mating structures and sensory and motor neurons. Thus, in order for all these organs to be formed, it is essential that the pattern of cell fusions be tightly controlled. To define the spatiotemporal constraints of cell fusion in C. elegans, the order of 
events in which epithelial cells fuse was studied (Figure 1). To study cell boundaries, apical junctions (AJs) were monitored during fusion using the MH27 monoclonal antibody that recognizes the AJM-1 protein (Francis and Waterston, 1991; Koppen et al., 2001). Using confocal microscopy and 3D reconstructions the sequence of fusions was studied (Figure 2; Podbilewicz and White, 1994). Hypodermal cell fusions start after migration of dorsal epithelial cells. Epidermal fusions usually start in the anterior dorsal epidermis and continue posteriorly. Thus, the fusions in the epidermis are not completely invariant. This is in contrast to the sequence of cell fusions in the vulva that are invariant in C. elegans (Sharma-Kishore et al., 1999). While in other nematode species the vulval cell fusion sequences are different than in C. elegans, they are invariant between animals of the same species (Kolotuev and Podbilewicz, 2004; Louvet-Vallee et al., 2003; See Figure 1 and Figure 2 for more details). The timing and location of postembryonic fusions in the epidermis, vulva, uterus and male tail have been studied in C. elegans and in related nematode species (Figure 2; Newman et al., 1996; Nguyen et al., 1999; Sharma-Kishore et al., 1999). These studies complement the observations of cell fusions obtained by electron microscopy and show intermediates in the sequence of cell fusions during development (Albertson and Thomson, 1976; Newman et al., 1996; Nguyen et al., 1999; Sharma-Kishore et al., 1999; Sulston et al., 1983; White, 1988). See Shemer and Podbilewicz (2000) for a detailed review of cell fusion events.

A

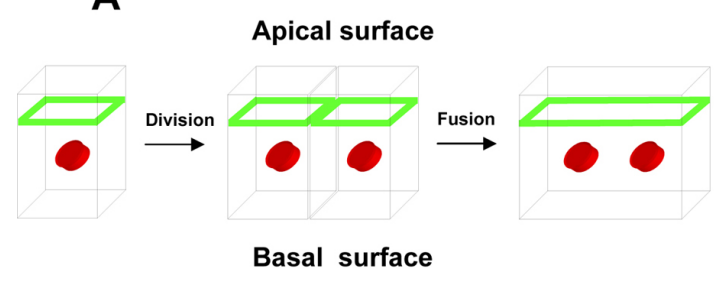

B

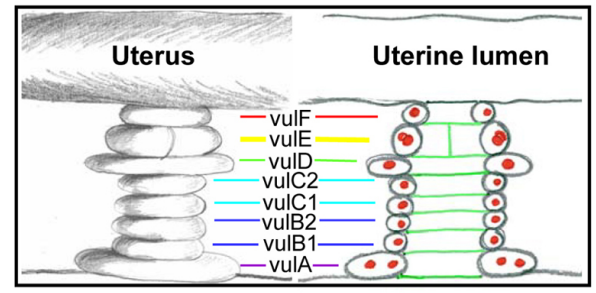

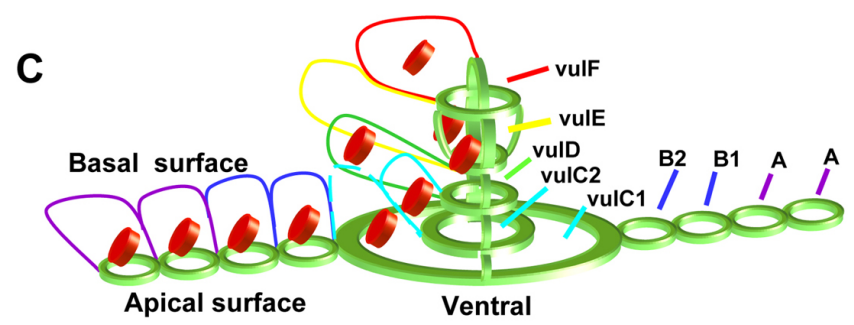
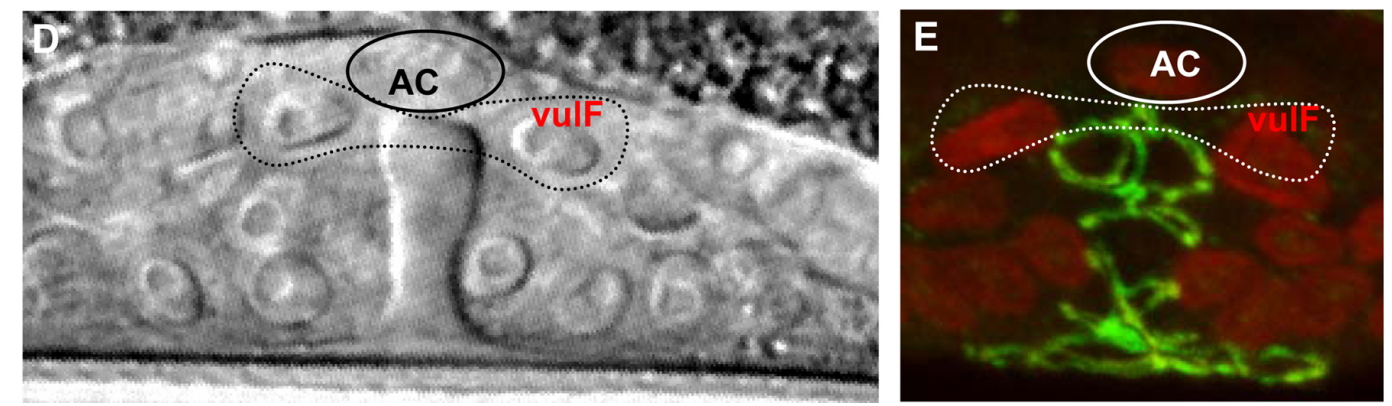

Figure 2. Changes in the morphology of apical junctions (AJ) reveal cell behavior during vulva formation. The monoclonal antibody MH27 stains AJs that represent the apical borders of epithelial cells including all vulval and hypodermal cells in C. elegans, P.pacificus and other nematodes (Baird et al., 1991; Fitch, 1997; Kolotuev and Podbilewicz, 2004; Louvet-Vallee et al., 2003). Nuclear staining is used to confirm observations concerning the junctions. Shown are negative micrographs of the junctions and schematic drawings based on detailed analysis of rotations and 3D views of the particular image. Note that the apical side of the vulva primordium is facing the ventral region of the animal and during morphogenesis the apical junctions face the lumen of the vulva. (A) Graphical representation of immunofluorescent staining in epithelial cells. Green represents the AJ belt; red cylinders represent nuclei in cells. This is a simplified model of the fusion process at the border between two neighboring cells. The disappearance of the AJ borders represents the fusion process based on EM and other studies (Podbilewicz and White, 1994; Sharma-Kishore et al., 1999) (B) Stack of vulva with 8 toroidal cells (right, VulA-VulF) and the cross section through the vulva (left). The vulva is from a late J3 stage hermaphrodite of P. pacificus after completion of invagination and intratoroidal fusions. Green lines represent AJs and red are nuclei. (C) A twenty cells stage vulva primordium after completion of cell proliferation but before initiation of cell fusion events in P. pacificus. Four toroids in the center are already formed. In the left side of the picture see the staining of AJs, the nuclei and the basolateral domains based on Nomarski images. Right side shows only the apical AJs without the nuclei and the estimated positions of the basolateral borders. (D) Nomarski image of vulva from middle J3 stage. AC - anchor cell. The dotted line represents the position of the vulF ring containing two nuclei and their nucleoli. The stage of vulva development in this micrograph corresponds almost exactly to the stage of vulva in panel E. Unlike the Christmas tree invagination shape of $C$. elegans vulva, in $P$. pacificus the vulva has a bell shape. (E) Double stained image of vulva middle $\mathrm{J} 3$ stage in $P$. pacificus. Green lines represent AJ and red are nuclei. Dotted line sketches estimated position of the vulF toroid based on many observations including Nomarski optics as shown in panel D. AC - anchor cell. Reproduced from Kolotuev and Podbilewicz (2004), Copyright (2004), with permission from Elsevier. 


\section{Cell biology of plasma membrane fusion}

A major advance in the understanding of developmental cell fusion was the development of a system to reproducibly observe ongoing cell fusions within a live organism. Using multiphoton laser scanning microscopy, it is possible to follow the dynamics of cell membranes during cell fusion with four-dimensional reconstruction of live embryos labeled with the vital fluorescent membrane probe FM-4-64 (Mohler et al., 1998). Syncytiogenesis is followed as the dynamic disappearance of lateral membranes and AJs labeled with AJM-1::GFP (Figure 2A and Figure 3B). Fusion appears to originate close to the apical junction and to expand along the membranes and basally generating an enlarging fusion wave (Figure 3). The complete elimination of the membranes between two fusing cells takes about $30 \mathrm{~min}$ (Mohler et al., 1998). The expansion of the fusion zone is accompanied by the migration of the AJ marker AJM-1::GFP from an apical to a basal position (Figure 3C). Disappearance of the basally located AJM-1::GFP protein occurs only 5-10 minutes after the initiation of membrane fusion (Mohler et al., 1998). However, the loss of AJs is not required for all cell fusions since dorsal and ventral cells fuse in the absence of AJs in the contact zone (Podbilewicz and White, 1994) and myoepithelial cells in the pharynx fuse without disassembling the AJs that remain in the apical side of the syncytia (Shemer et al., 2004).

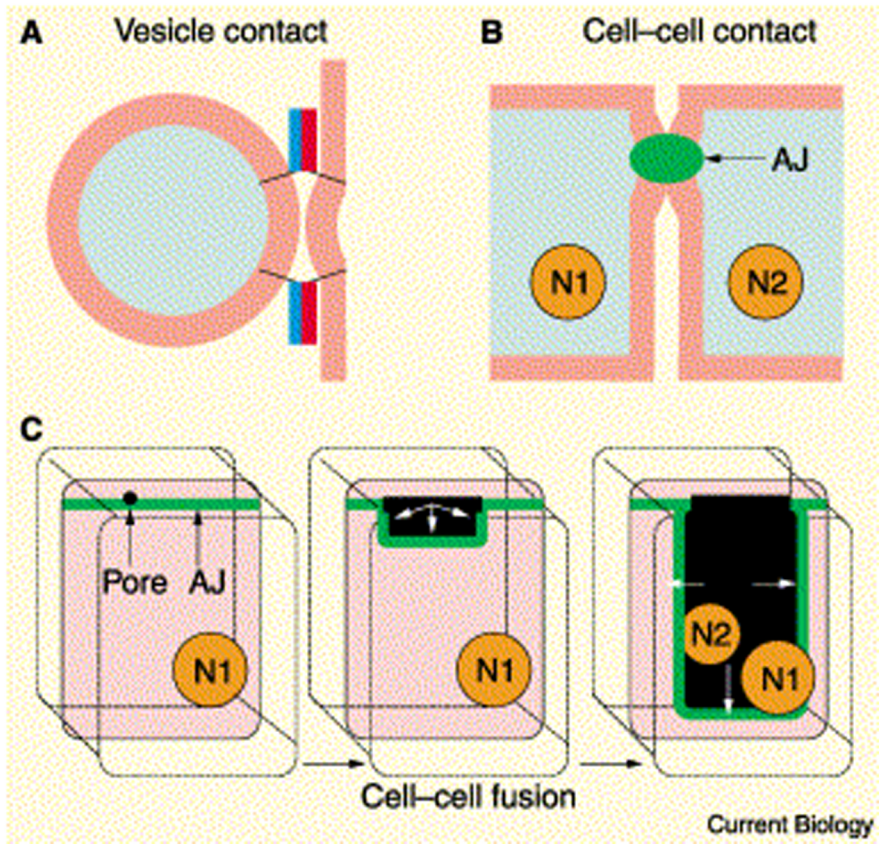

Figure 3. Membrane fusion mechanisms. (A) The coiled-coil domains of SNAREs bring vesicle and target membranes within close proximity, facilitating fusion. (B) In epidermal cell fusion in C. elegans, the apical junctions (AJ) hold the epidermal cells together where cell fusion is initiated. (C) A fusion pore forms at the apical junction of the membrane barrier and spreads outward behind the migrating junction. The two nuclei of the adjacent cells (N1, N2) share a common cytoplasm after fusion. Reproduced from Witze and Rothman (2002), Copyright (2002), with permission from Elsevier.

TEM on embryos fixed while fusion events were in progress showed vesiculation of membranes at the fusing zone. The irregular vesicles observed (10-50 $\mathrm{nm}$ in diameter) were interpreted as part of a cellular fusion machinery that initiates membrane merger by the formation of a single unique pore at the apex of the fusing cells that expands through radial internalization of the cell membranes (Mohler et al., 1998). However, alternative mechanisms could account for the observations (Podbilewicz and Chernomordik, 2005). Fusion pores can be detected by electrophysiology or by following redistribution of cytoplasmic aqueous probes (e.g., GFP; Mohler et al., 2002; Shemer et al., 2004). However, these methods cannot be used to study the expansion of fusion pores between cells from a few nanometers to micrometers in diameter. The mechanisms responsible for late fusion stages and their dependence on the fusogenic proteins that initiated pore formation remain largely unexplored even in well characterized viral-cell fusion systems (Leikina et al., 2004; Podbilewicz and Chernomordik, 2005). In summary, cell fusion in embryonic dorsal epithelial cells has been analyzed in great detail by confocal microscopy using membrane fluorescent probes (FM4-64; Mohler, 1999; Mohler et al., 1998; Mohler and White, 1998), apical junction markers (AJM-1::GFP; Mohler et al., 1998; Rabin and Podbilewicz, 2000) and cytoplasmic aqueous fluorescent probes (Mohler et al., 2002; Shemer et al., 2004) allowing the direct observation of membrane disappearance, pore expansion and cytoplasmic content mixing. TEM studies of the same cells have shown vesiculation as a possible intermediate in pore expansion (Mohler et al., 1998). Other cell fusions during 
morphogenesis of the tail showed much larger vesicles but no small irregular vesiculation of the membranes (Nguyen et al., 1999). The vesicles may be recycled to a different domain of the plasma membrane where they can fuse (exocytosis). The overall result of this membrane recycling process may transfer transverse membranes to longitudinal areas allowing efficient elongation of the animal (Podbilewicz, 2000; Shemer and Podbilewicz, 2000). More recently, multiple stable pore intermediates $(20-50 \mathrm{~nm}$ in diameter) were identified in pharyngeal myoepithelial and epidermal cells in eff-1 mutants (Figure 4; Gattegno et al., unpublished results; Shemer et al., 2004). The emerging picture suggests tissue-specificity in the mechanisms of initiation and expansion of fusion pores in C. elegans offering an amazing system to dissect the stages in the universal and largely unknown process of cell fusion.

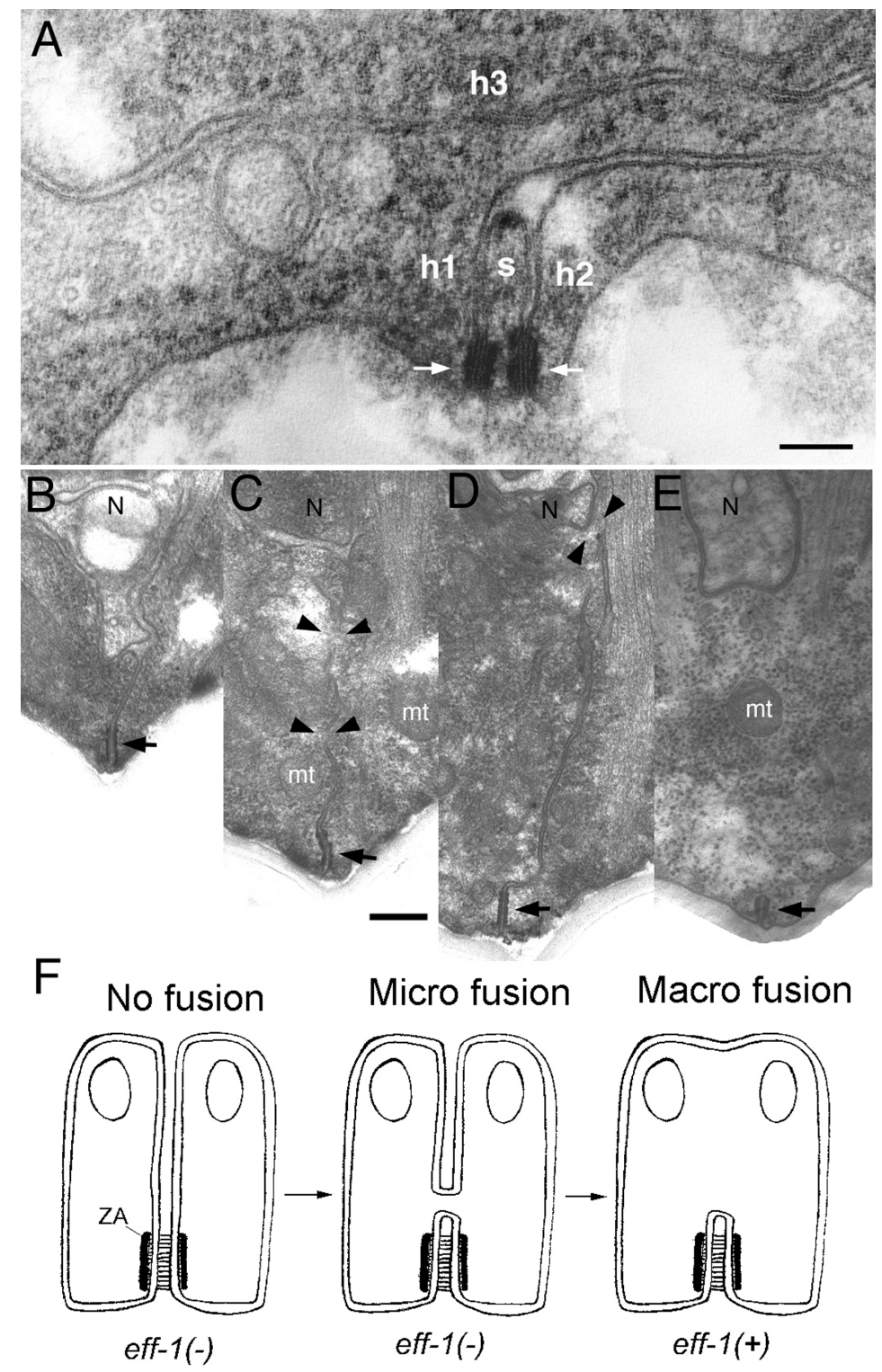

Figure 4. TEM of unfused epidermal and muscle cells. (A) Transverse thin section of mutant eff-1(hy21) L4 grown at the restrictive temperature shows normal ultrastructure of the hypodermal membranes, where the separation between apposing plasma membranes that failed to fuse is generally between 9 to $13 \mathrm{~nm}$ as in wild-type. The ultrastructure of the AJs (arrows) and membranes appears normal. Here, a seam cell process (s) narrows and three neighboring hypodermal cells (h1, h2 and h3) remain unfused along the lateral body wall. Lateral cuticle lies along bottom edge of panel. (B-E) TEM of pharyngeal muscle pairs shows variable fusion failure in a mutant eff-1(hy21) adult grown at the restrictive temperature or successful fusion in wild-type cells. (B) Two cells have failed to fuse, leaving a persistent cell border running from the neuron process (N) to the apical junction (AJ indicated by arrow). (C-D) Above the AJ, two pairs of eff-1(hy21) mutant cells have formed microfusions (arrowheads), which are so small that no mitochondria (mt) could pass.(E) Two wild-type cells have fully fused below the neuron process (N), leaving behind a complete AJ on the plasma membrane of the fused cell pair.(F) Model showing a pathway for pharyngeal muscle homotypic fusion based on TEM intermediates. Zonula adherens (ZA) is a component of the AJ (Knust and Bossinger, 2002) (B-E). The scale bars represent $100 \mathrm{~nm}$. Reproduced from Shemer et al. (2004), Copyright (2004), with permission from Elsevier. 


\section{Genetics of cell fusion}

Genes encoding fusogenic proteins required for the fusion of enveloped viruses (Earp et al., 2005) and intracellular membrane traffic (See Figure 3A; Jahn et al., 2003) have been identified and characterized. However, developmental cell fusion proteins are responsible for cell attachment before fusion or regulation of cell fusion (Chen and Olson, 2004; Chen and Olson, 2005; Kontani and Rothman, 2005; Shemer and Podbilewicz, 2003; Stein et al., 2004). Over the last decade a few attempts have been made to isolate mutations that specifically block or affect cell fusion in worms (Alper and Kenyon, 2001; Gattegno, 2003; Labouesse, 1997; Mohler et al., 2002; Podbilewicz, 2000; Podbilewicz and Chernomordik, 2005; Shemer and Podbilewicz, 2000; Shemer and Podbilewicz, 2003; Terns et al., 1997). Many successful screens have been designed to isolate spermatogenesis and oogenesis defective mutants that block fertilization (Singson et al., 1998; Xu and Sternberg, 2003). Still, very few mutants are candidates to affect stages after attachment of the two plasma membranes (see Control of oocyte meiotic maturation and fertilization and L'Hernault, 1997; Singson, 2001). Only recently mutations that block most somatic cell fusions in C. elegans were obtained, and they identified one gene that appears to be essential for the merger of the plasma membranes without affecting attachment or other pre-fusion processes (Kontani and Rothman, 2005; Mohler et al., 2002; Gattegno, T., Assaf, N. and BP, unpublished results).

\section{4. eff-1 is necessary for most, but not all, cell fusion events in C. elegans}

eff- 1 encodes a strong candidate developmental fusogen that is expressed in the fusion competent cells prior to cell membrane fusion. Moreover, eff- 1 mutant cells are wild-type in events prior to cell membrane fusion. Still the mutant cells fail to fuse and they develop as unfused epithelia within subviable animals containing morphological, behavioral and fertility defects (Cassata et al., 2005; Gattegno, 2003; Mohler et al., 2002; Shemer, 2002; Shemer and Podbilewicz, 2002; Shemer and Podbilewicz, 2003; Shemer et al., 2004; Figure 5). eff-1 is the founder of a novel gene family encoding membrane and secreted proteins conserved within nematodes. No homologous genes have been identified in species outside nematodes (Shemer and Podbilewicz, 2003). Genetic and cell biological evidence indicates that eff- 1 activity is both necessary (Mohler et al., 2002) and sufficient (Shemer et al., 2004) to fuse epithelial and myoepithelial cells of the epidermis, vulva, uterus and pharynx in vivo. However, eff-l is not required in at least one fusion event in worms, the fusion between the anchor cell and the utse cells (Shemer et al., 2004); Anna Newman, personal communication). eff- 1 encodes at least four alternatively-spliced isoforms, two predicted type-I membrane glycoproteins (eff- $1 \mathrm{~A}$ and eff- $1 \mathrm{~B}$ ) and two secreted proteins (eff- $1 \mathrm{C}$ and eff- $1 \mathrm{D}$; Shemer and Podbilewicz, 2003). eff- 1 contains a putative fusion peptide within the protein similar to some class II viral fusogens (Wormbase; Shemer and Podbilewicz, 2003).

Recently, ectopic expression of genomic eff-1A::GFP showed dynamic GFP localization from the cytoplasm to the sites of cell-cell contact, prior to, and during, cell fusion (del Campo et al., 2005). The functions of two extracellular domains of eff- 1 that had been hypothesized to have roles in membrane fusion have been tested (Shemer and Podbilewicz, 2003). While transgenic proteins mutated in a putative phospholipase A2 active site rescued a weak eff- 1 mutant, two independent mutations in the putative hydrophobic fusion peptide, failed to rescue (del Campo et al., 2005). However, the putative fusion peptide mutated proteins were not expressed on the surface. Thus, the putative fusion peptide is required for correct folding, transport or localization to the site of contact and the direct function of this domain on cell fusion has not been determined (del Campo et al., 2005). It was proposed that homotypic interactions of eff-1A proteins facilitate cell fusion by bringing the membranes into close contact in analogy to SNARE-mediated intracellular fusion (See Figure 3A; del Campo et al., 2005). Since these experiments were done in the background of weak eff- 1 mutations, it is conceivable that the ectopic expression of eff- 1 protein isoforms can interact and rescue the endogenous partially active eff- 1 mutant proteins. Further structure-function analyses of eff- 1 isoforms, genetic mosaic analyses and in vitro reconstitution of membrane fusion will determine whether eff- 1 alone is sufficient to induce membrane fusion. Nevertheless, it is still possible that eff- 1 controls fusion at a post-binding, pre-membrane merger stage. Based on electron microscopic analyses of intermediates of cell fusion in eff- 1 mutants, it appears that eff- 1 is required for both initiation and expansion of fusion pores (Figure 4), similar to the well characterized fusogen of Influenza virus (Gattegno et al., unpublished results; Leikina et al., 2004; Podbilewicz and Chernomordik, 2005; Shemer et al., 2004). 


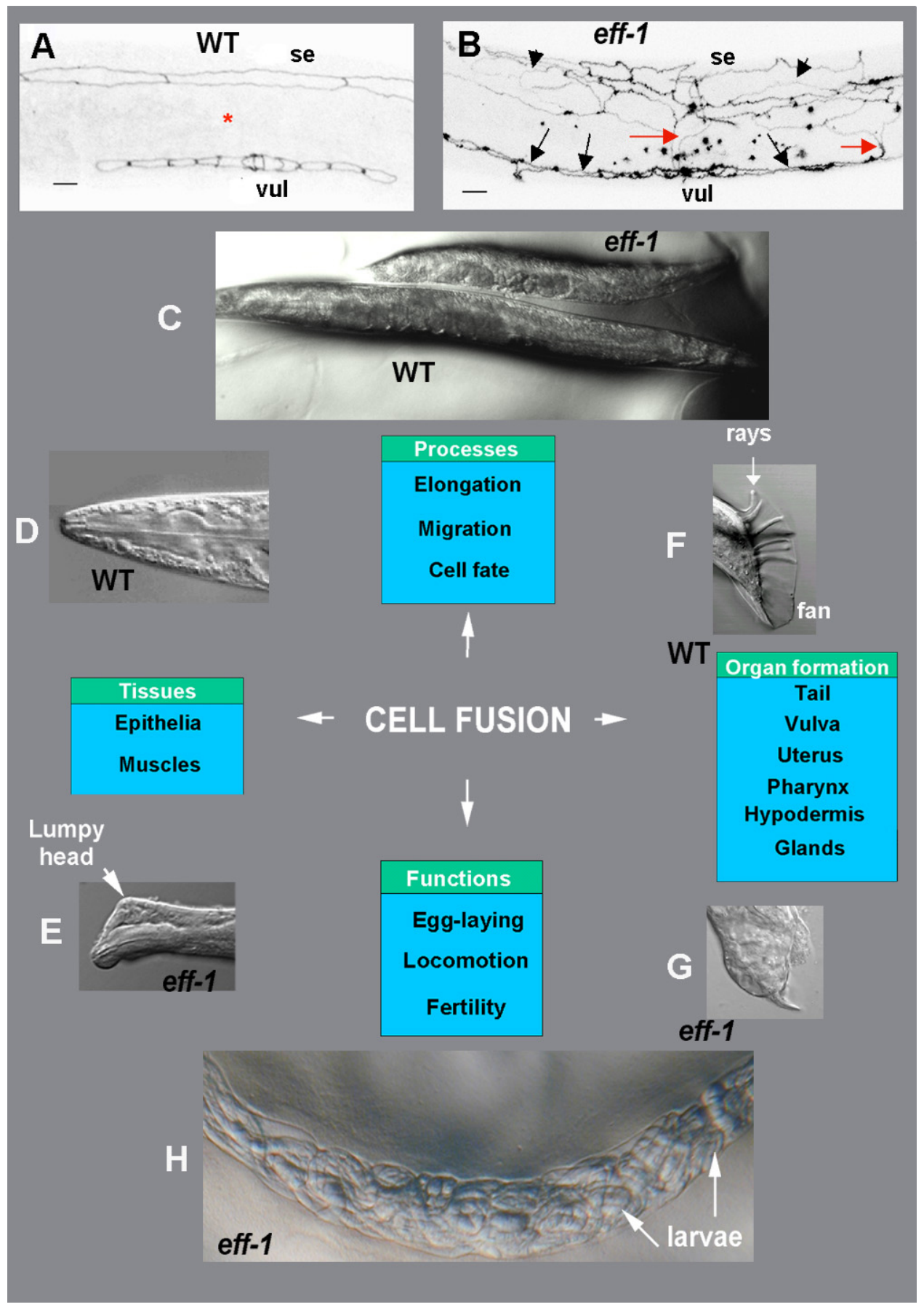

Figure 5. Cell fusion is essential for normal behavior and morphogenesis in C. elegans. Fluorescence negative images (A, B) and Nomarski (D-H) micrographs of wild-type and eff-1 mutant C. elegans. In all pictures anterior is to the left and dorsal up. (A, B) Staining of the apical domains of epithelial cells using the anti-ZA MH27 antibody. (A) In wild-type (WT) animals lateral hypodermal seam cells (se) divide with the successive fusion of the non-stem daughter cells to the hypodermal syncytium (red asterisk). The non-fusing seam cells ultimately form two lateral rows along the body (one row is seen in this focal plain). (B) In eff-1 mutant animals, after failing to fuse with the surrounding epidermis, the daughter cells of the seam cells migrate throughout the epidermis (arrowheads) and form a misarranged net (Mohler et al., 2002). This abnormal migration is also exhibited in vulval ectopically unfused cells (vul) that extend across the ventral surface (black arrows) and meet with the migrating seam cells (red arrows). (C) Cell fusion defects in eff-1 mutants cause inhibition of elongation and result in short and dumpy animals. (D, E) Details of heads in wild-type (D) and eff-1 mutant (E), showing a Lumpy phenotype expressed as hypodermal defects throughout the body and especially near the head (arrow). (F) In males, the correct patterning and positioning of special sensilla (rays), enveloped in a cuticular fan, is based on earlier cell fusion between four cells in the tip of the tail (Emmons and Sternberg, 1997). This event, followed by retraction of the newly-formed syncytium and secretion of fluid to the extracellular space, allows essential shape changes in the tip of the tail (Nguyen et al., 1999). (G) When cell fusion is blocked, the cells cannot retract, and the normal formation of the male-specific tip of the tail is disrupted, resulting in altered rays and fan and in mating disability. $(\mathrm{H})$ eff-1 mutants are egg-laying defective. Embryos that fail to get out of the uterus, develop to L1 larvae, eat their mother's tissues and get out of their body (a "bag of worms" phenotype). Reproduced from Shemer and Podbilewicz (2003), Copyright (2003), with permission from Wiley. 


\section{Regulation of cell fusion}

\subsection{Transcriptional regulation of cell fusion}

During morphogenesis the main body epidermis is patterned in three distinct regions with different fusogenic activities (Figure 1; Ding et al., 2004; Michaux et al., 2001; Priess and Hirsh, 1986; Simske and Hardin, 2001): dorsal, lateral and ventral. 1) Two rows of dorsal cells interdigitate forming a single row of cells that fuse forming the hyp6 and hyp7 syncytia as the embryo elongates (Podbilewicz and White, 1994; Priess and Hirsh, 1986; Sulston et al., 1983). 2) Two independent rows of lateral seam cells that elongate but do not fuse during embryogenesis, but their descendants fuse with hyp7, generate neurons or maintain the seam cells during postembryonic development. 3) Two rows of ventral P blast cells that do not fuse in the embryo, but their descendants either migrate and fuse with hyp7 or divide and differentiate into neuronal, vulval, anal or male tail tissues during larval development (Figure 6; Sulston and Horvitz, 1977). Different transcription factors have been identified as regulators of the fusion activities that pattern the epidermis and associated sexual and neuronal organs (Table 1; see also Transcriptional regulation and Transcription mechanisms).

A. P cells migrate into the ventral cord (ventral view) - early L1

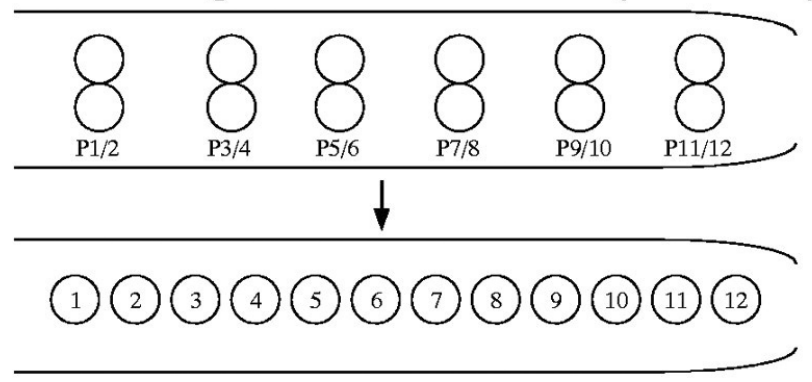

B. 12 Pn.p cells line the ventral surface (lateral view) - late L1

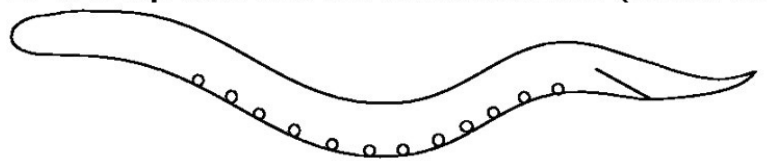

C. Hermaphrodite

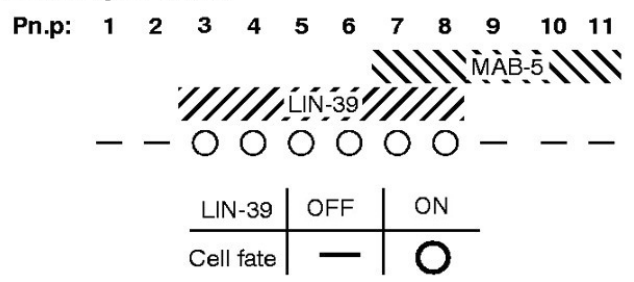

D. Male

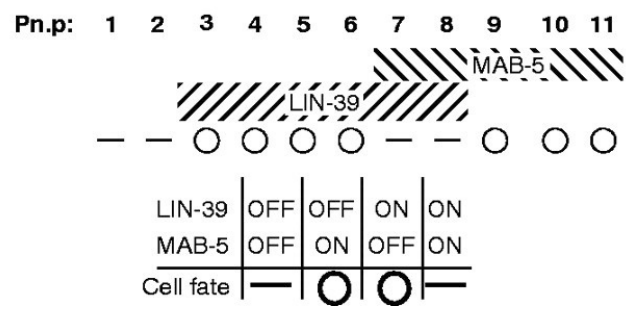

Figure 6. The Pn.p cell fusion pattern is regulated by the Hox genes lin-39 and mab-5. (A) Ventral views of early-L1 (top) and mid-L1 (bottom) larvae. Six pairs of epidermal $\mathrm{P}$ blast cells initially lie along the ventral surface (top). During L1, the P cells migrate around each other so that a row of $12 \mathrm{P}$ cells lines the ventral surface (bottom). Shortly after they migrate into the ventral cord, the $\mathrm{P}$ cells divide. The anterior (Pn.a) daughters become neuroblasts, while the posterior (Pn.p) daughters remain epidermal. Anterior is towards the left. (B) Lateral view of a late L1 larva with the 12 ventrally located Pn.p cells shown. Some of the Pn.p cells fuse with hyp7, which is located more dorsally along most of the mid-body region. (C, D) Pn.p cell fusion in wild-type hermaphrodite (C) and male (D). White circles indicate Pn.p cells that remain unfused, short horizontal lines indicate cells that fuse with the hyp7 syncytium. Hox gene expression domains are similar in both sexes, as indicated in hatched regions. The tables underneath show how Hox gene expression information is interpreted in the cell fusion decision. Reproduced from Alper and Kenyon (2002), Copyright (2002), with permission from The Company of Biologists. 
Table 1. Regulators of developmental cell fusion in C. elegans

\begin{tabular}{|c|c|c|}
\hline Gene & $\begin{array}{l}\text { Protein structure and proposed } \\
\text { function }\end{array}$ & References \\
\hline \multicolumn{3}{|l|}{ Ventral cell fusions } \\
\hline lin-39 & $\begin{array}{l}\text { Hox }(D f d / S c r) \text {-represses } \text { eff-1 } \\
\text { expression in hermaphrodites }\end{array}$ & \begin{tabular}{|l|} 
Clark et al., 1993; Maloof and \\
Kenyon, 1998; Shemer and \\
Podbilewicz, 2002; Wang et al., 1993
\end{tabular} \\
\hline $\operatorname{lin}-39$ & $\begin{array}{l}\text { Hox }(D f d / S c r) \text {-inhibits fusion in } \\
\text { males when } m a b-5 \text { is } O F F\end{array}$ & \begin{tabular}{|l|} 
Clark et al., 1993; Maloof and \\
Kenyon, 1998; Wang et al., 1993
\end{tabular} \\
\hline lin-39+mab-5 & $\begin{array}{l}\text { Hox }(D f d / S c r+A n t p) \text { promote fusion } \\
\text { in males }\end{array}$ & $\begin{array}{l}\text { Clark et al., 1993; Salser and } \\
\text { Kenyon, 1994; Wang et al., } 1993\end{array}$ \\
\hline$m a b-5$ & $\begin{array}{l}\text { Hox (Antp) inhibits fusion in males } \\
\text { when lin-39 is OFF }\end{array}$ & $\begin{array}{l}\text { Alper and Kenyon, 2001; Kenyon, } \\
1986\end{array}$ \\
\hline ceh-20 & $\begin{array}{l}\text { Hox co-factor }(e x d / p b x) \text {-represses } \\
\text { eff-1 expression }\end{array}$ & Shemer and Podbilewicz, 2002 \\
\hline$n h r-25$ & $\begin{array}{l}\text { Ftz-F1/SF1 Hox co-factor-represses } \\
\text { fusion with lin-39in } \mathrm{P}(3-8) . \mathrm{p}\end{array}$ & Chen et al., 2004 \\
\hline$n h r-25$ & $\begin{array}{l}\text { Ftz-F1/SF1 co-factor-promotes } \\
\text { fusion in non-VPCs }\end{array}$ & Chen et al., 2004 \\
\hline acn-1 & $\begin{array}{l}\text { Angiotensin-converting } \\
\text { enzyme-transcriptional target of } \\
n h r-25\end{array}$ & Brooks et al., 2003; Chen et al., 2004 \\
\hline ref-1 & $\begin{array}{l}\text { bHLH TF (hairy)-inhibits mab-5 } \\
\text { activity and lin-39 expression }\end{array}$ & Alper and Kenyon, 2001 \\
\hline egl-27 & $\begin{array}{l}\text { Chromatin remodelling-regulates } \\
\text { Pn.p cell fusion in both sexes }\end{array}$ & Ch'ng and Kenyon, 1999 \\
\hline$r e f-2$ & $\begin{array}{l}\text { Zinc-finger TF-prevents Pn.p fusion } \\
\text { in L1 }\end{array}$ & Alper and Kenyon, 2002 \\
\hline egl-18/elt-6 & $\begin{array}{l}\text { GATA factors-repress cell fusion } \\
\text { L2-L4; targets of lin-39/ceh-20 }\end{array}$ & Koh et al., 2004; Koh et al., 2002 \\
\hline sem-4 & $\begin{array}{l}\text { Zinc-finger TF-positively regulates } \\
\text { lin-39, preventing fusion }\end{array}$ & Grant et al., 2000 \\
\hline bar-1 & $\begin{array}{l}\text { Wnt pathway } \\
\text { (beta-catenin)-positively regulates } \\
\text { lin-39 }\end{array}$ & Eisenmann et al., 1998 \\
\hline apr-1 & $\begin{array}{l}\text { Wnt pathway (APC related } \\
\text { factor)-activates bar-1 }\end{array}$ & Hoier et al., 2000 \\
\hline let-60 & $\begin{array}{l}\text { Ras inhibits fusion L1-L3; promotes } \\
\text { fusion in late vulva development }\end{array}$ & Han et al., 1990; Shemer et al., 2000 \\
\hline SynMuv class A (e.g., lin-15a) & $\begin{array}{l}\text { TFs, NURD complex components } \\
\text { and chromatin remodeling-work with } \\
\text { class B to antagonize Ras pathway } \\
\text { signaling }\end{array}$ & $\begin{array}{l}\text { Chen and Han, 2001; Fay and Han, } \\
\text { 2000; Herman and Hedgecock, } 1990\end{array}$ \\
\hline SynMuv class B (e.g., lin-35/Rb) & $\begin{array}{l}\text { TFs, Rb/E2F complex components } \\
\text { and chromatin remodeling-work with } \\
\text { class A to antagonize Ras pathway } \\
\text { signaling promoting fusion }\end{array}$ & $\begin{array}{l}\text { Chen and Han, 2001; Fay and Han, } \\
\text { 2000; Herman and Hedgecock, 1990; } \\
\text { Myers and Greenwald, 2005 }\end{array}$ \\
\hline SynMuv class C (e.g.,TRRAP) & Tip60/NuA4-like histone & Ceol and Horvitz, 2004 \\
\hline
\end{tabular}




\begin{tabular}{|c|c|c|}
\hline Gene & $\begin{array}{l}\text { Protein structure and proposed } \\
\text { function }\end{array}$ & References \\
\hline & $\begin{array}{l}\text { acetyltransferase complex and P400 } \\
\text { work with class A and B to } \\
\text { antagonize Ras pathway signaling }\end{array}$ & \\
\hline fus-1 & $\begin{array}{l}\text { E subunit of V-ATPase-represses } \\
\text { eff- } 1 \text { activity; late embryogenesis }\end{array}$ & Kontani et al., 2005 \\
\hline \multicolumn{3}{|c|}{ Lateral cell fusions } \\
\hline$n h r-25$ & $\begin{array}{l}\text { Ftz-F1/SF1 TF-promotes cell fusion } \\
\text { and/or differentiation }\end{array}$ & Chen et al., 2004 \\
\hline acn-1 & $\begin{array}{l}\text { Angiotensin-converting } \\
\text { enzyme-Molting and morphogenesis }\end{array}$ & Brooks et al., 2003 \\
\hline $\operatorname{lin}-29$ & $\begin{array}{l}\text { Zinc-finger TF-promotes fusion in L4 } \\
\text { molt; heterochronic pathway }\end{array}$ & $\begin{array}{l}\text { Ambros and Moss, 1994; Rougvie } \\
\text { and Ambros, } 1995\end{array}$ \\
\hline egl-18/elt-6 & GATA factors-repress cell fusion & Koh and Rothman, 2001 \\
\hline ceh-16 & $\begin{array}{l}\text { Homeobox TF (engrailed)-represses } \\
\text { eff-1 expression }\end{array}$ & Cassata et al., 2005 \\
\hline $\operatorname{lin}-25$ & $\begin{array}{l}\text { Novel protein TF?-overexpression } \\
\text { disrupts cell fusion }\end{array}$ & Nilsson et al., 1998 \\
\hline \multicolumn{3}{|c|}{ Dorsal cell fusions } \\
\hline ceh-13 & $\begin{array}{l}\text { Hox (labial)-promotes some anterior } \\
\text { cell fusions }\end{array}$ & Brunschwig et al., 1999 \\
\hline$i d f-1$ & Nd-promotes embryonic cell fusion & Gattegno, 1998; Gattegno, 2003 \\
\hline fus-1 & $\begin{array}{l}\text { E subunit of V-ATPase-represses } \\
\text { eff-lactivity, late embryogenesis }\end{array}$ & Kontani et al., 2005 \\
\hline \multicolumn{3}{|c|}{ Male tip of the tail cell fusions } \\
\hline tlp-1 & $\begin{array}{l}\text { Zinc-finger TF-required for polarity } \\
\text { of T lineage and hyp }(8-10) \text { fusions }\end{array}$ & Zhao et al., 2002 \\
\hline lep-1 & $\begin{array}{l}\text { Nd-Required for correct timing of } \\
\text { cell fusions and morphogenesis }\end{array}$ & Nguyen et al., 1999; Zhao et al., 2002 \\
\hline \multicolumn{3}{|c|}{$\begin{array}{l}\text { Anchor cell-uterine seam cell } \\
\text { fusion (AC-utse; vulval-uterine } \\
\text { connection) }\end{array}$} \\
\hline $\operatorname{lin-11}$ & $\begin{array}{l}\text { LIM -homeobox TF-differentiation } \\
\text { of cells that fuse with AC }\end{array}$ & Newman et al., 1999 \\
\hline cog-2/egl-13 & $\begin{array}{l}\text { Sox-domain TF-maintains fates of } \\
\text { cells that fuse with AC }\end{array}$ & $\begin{array}{l}\text { Cinar et al., 2003; Hanna-Rose and } \\
\text { Han, } 1999\end{array}$ \\
\hline smo-1 & $\begin{array}{l}\text { SUMO-1-Small ubiquitin-like } \\
\text { modifier-Modifies lin-11 activity }\end{array}$ & Broday et al., 2004 \\
\hline ty 10 & $\begin{array}{l}\text { sec-18/nsf homolog-intracellular } \\
\text { vesicular fusion, promotes AC fusion }\end{array}$ & A. Newman, personal communication \\
\hline \multicolumn{3}{|c|}{$\begin{array}{l}\text { Epithelial and pharyngeal cell } \\
\text { fusions but not } \mathrm{AC} \text {-utse cell fusion }\end{array}$} \\
\hline eff-1 & $\begin{array}{l}\text { Novel transmembrane and secreted } \\
\text { isoforms-fusion machinery }\end{array}$ & $\begin{array}{l}\text { Mohler et al., 2002; Shemer et al., } \\
2004\end{array}$ \\
\hline \multicolumn{3}{|c|}{$\begin{array}{l}\text { Identity and putative functions (if mentioned) of genes that control cell fusion during C. elegans development.Class } \\
\text { A of the SynMuv genes works redundantly with class B genes to promote fusion. Class C works with classes A and } \\
\text { B. Each one of these classes contains several genes. nd- not determined TF-transcription factor. Modified from } \\
\text { Shemer and Podbilewicz (2003), Copyright (2003), with permission from Wiley. }\end{array}$} \\
\hline
\end{tabular}




\subsection{Ventral cell fusions}

During morphogenesis six ventral cells fuse to 17 dorsal cells to form the large syncytium hyp 7 in the embryo. However, $12 \mathrm{P}$ cells covering most of the ventral epidermis do not fuse in the embryo. In the L1, six posterior descendants of the P cells (P(3-8).p; the ventral precursor cells, VPCs) are each competent to generate vulval cells in the hermaphrodite. In the wild-type L3, only the nearest VPCs to the uterine anchor cell (AC) generate the 22 nuclei of the vulva, while the three others fuse to hyp7. The vulval primordial cells divide, migrate and fuse in a stereotyped manner to form an epidermal tube during the L3 and L4 stages (Greenwald, 1997; Kornfeld, 1997; Michaux et al., 2001; Podbilewicz and White, 1994; Sharma-Kishore et al., 1999; Sulston and Horvitz, 1977; Sulston et al., 1983; Wang and Sternberg, 2001). For an overview of ventral cell biology in hermaphrodites and males (see Figure 1 and Figure 6 and the chapters: Epidermal morphogenesis, Hermaphrodite cell-fate specification, Male development, and Vulval development).

\subsubsection{Hox genes protect specific cells from fusion allowing organ formation}

The six Hox genes in C. elegans are expressed and determine cell fates along the antero-posterior body axis (Brunschwig et al., 1999; Chisholm, 1991; Clark et al., 1993; Van Auken et al., 2000; Wang et al., 1993; See chapter on Hox genes). In the L1, the Hox genes lin-39/Sex combs reduced/Deformed and mab-5/Antennapedia regulate cell fusion of the Pn.p cells to hyp7 (Figure 6). P(3-8).p cells express lin-39 and P(7-11).p express mab-5 in both sexes (Maloof and Kenyon, 1998; Salser and Kenyon, 1994; Wang et al., 1993). lin-39 prevents fusion of P(3-8).p (vulva precursor cells; VPCs) in the hermaphrodites (Clark et al., 1993; Wang et al., 1993) by repression of eff-1 expression (Shemer and Podbilewicz, 2002). The lin-39 prevention of cell fusion of P(3-8).p is maintained until P(5-7).p cells are induced in the L3 (Maloof and Kenyon, 1998; Shemer and Podbilewicz, 2002). Wnt and Ras signaling control lin-39 activity in the VPCs (Chen and Han, 2001; Eisenmann et al., 1998; Maloof and Kenyon, 1998; see Wnt signaling).

In hermaphrodites mab-5 appears to be largely inactive in $\mathrm{P}(7-11) . \mathrm{p}$ during the $\mathrm{L} 1$ cell fusion fate decision (Figure 6C; see below). However, in mab-5 mutant worms, P11.p is sometimes transformed into P12.p (Kenyon, 1986) and in 15\% of the mab-5 (lf) hermaphrodites P11.p fails to fuse in the L1 (Alper and Kenyon, 2001). It has been shown that mab-5 has a dynamic and fine control over diverse cellular and morphogenetic activities (Salser et al., 1993). It is possible that mab-5 may also have a complex and dynamic activity in the posterior Pn.p cells during the L3 since some vulval phenotypes have been observed in mab-5 hermaphrodites (Clandinin et al., 1997) and mab-5 mutations in Pristionchus pacificus strongly affect vulva formation (Gutierrez et al., 2003; Jungblut et al., 2001; Jungblut and Sommer, 1998; Ira Kolotuev and BP, unpublished results; see Evolution of development in nematodes related to $C$. elegans).

\subsubsection{Hox cofactors}

eff-1 is also epistatic to ceh-20, encoding a known cofactor of lin-39 (Koh et al., 2002; Liu and Fire, 2000). ceh-20/Extradenticle may act in a complex with lin-39 and other cofactors to repress eff- 1 transcription (Shemer and Podbilewicz, 2002). $n h r-25 / \mathrm{Ftz}-\mathrm{F} 1 / \mathrm{SF} 1$ may also act as a cofactor of lin-39 during regulation of fusion in the Pn.p cells (Asahina et al., 2000; Chen et al., 2004; Gissendanner and Sluder, 2000). nhr-25 may act with lin-39 to repress fusion of $\mathrm{P}(3-8) . p$ while acting with another transcription factor in neighboring cells to promote cell fusion and cell shape dynamic changes (Chen et al., 2004; Silhankova et al., 2005). A potential transcriptional target of $n h r-25$ is acn-1, a gene encoding a member of the angiotensin-converting enzyme family (Brooks et al., 2003; Chen et al., 2004).

The following working model is emerging for the regulation of cell cycle and cell fusion effectors by Hox proteins and cofactors in the ventral epidermis. First, a complex of lin-39/ceh-20 (Koh et al., 2002; Liu and Fire, 2000) together with other transcription factors and cofactors represses eff- 1 -mediated plasma membrane fusion during competence and induction in the L1 and L3 respectively. Second, lin-39 also stimulates cell division. Third, VPCs that failed to fuse and to divide in lin-39;eff- 1 double mutants can perform other cellular behaviors characteristic of their normal great-granddaughters, such as formation of vulval rings (Shemer and Podbilewicz, 2002) and partial Mid-L4 expression of vulval markers like egl-17::GFP (Burdine et al., 1998; Cui and Han, 2003). Thus, in the absence of lin-39 activity, induction of the VPCs is independent of their patterns of cell division (sublineages) and a double block in cell fusion and cell cycle can allow cell differentiation (Shemer and Podbilewicz, 2002). Cell fusion inhibition is not sufficient for the VPCs to form a vulva because lin-39 is also required for these cells to proliferate. Although undivided VPCs do form vulval rings, these are non-functional 
(Shemer and Podbilewicz, 2002). Finally, during late stages in vulva morphogenesis, Ras appears to have a cell fusion promoting function (Shemer et al., 2000).

\subsubsection{L1-specific regulation of cell fusion by Hox, ref-1, ref-2 and egl-27}

Two transcription factors, egl-27 and ref-1, maintain mab-5 inactive in the hermaphrodite. In a screen for mutations that modify the pattern of Pn.p cell fusion, ref-1 (mu220; REgulator of Fusion-1) was isolated. ref-1 mutation affects Pn.p cell fusion early but not later during larval development (Figure 7). ref-1, a protein with two bHLH domains, allows fusion of posterior Pn.p cells in the hermaphrodites by inhibiting the sex-specific mab-5 activity (Alper and Kenyon, 2001). In addition, ref-1 functions together with mab-5 to prevent lin-39 expression in the posterior region allowing fusion of posterior Pn.p cells. The third action of ref- 1 is independent of $m a b-5$, ref- 1 can influence the Hox gene egl-5's ability to regulate Pn.p cell fusion (Alper and Kenyon, 2001). egl-27, a chromatin regulatory factor (Ch'ng and Kenyon, 1999; Herman et al., 1999; Solari et al., 1999), regulates Pn.p cell fusion in both sexes. In egl-27 mutant hermaphrodites, posterior Pn.p cells fail to fuse. egl-27 regulates expression of lin-39, mab-5 and egl-5 controlling fusion of specific ventral cells. In males, mab-5 and lin-39 inhibit each other's activity when expressed in the same Pn.p cell, resulting in fusion of these cells (See Figure 6D). In males, egl-27 permits the combinatorial interaction between lin-39 and mab-5. Thus, egl-27 activation appears to provide cell- and sex- specific regulation of Hox function that creates antero-posterior patterns of cell fusion (Ch'ng and Kenyon, 1999). egl-27 and ref-1 could directly, or indirectly through Hox and GATA factors and other cofactors, control transcription of eff- 1 along the antero-posterior axis to generate a complex pattern of Pn.p cell fusion (see below).
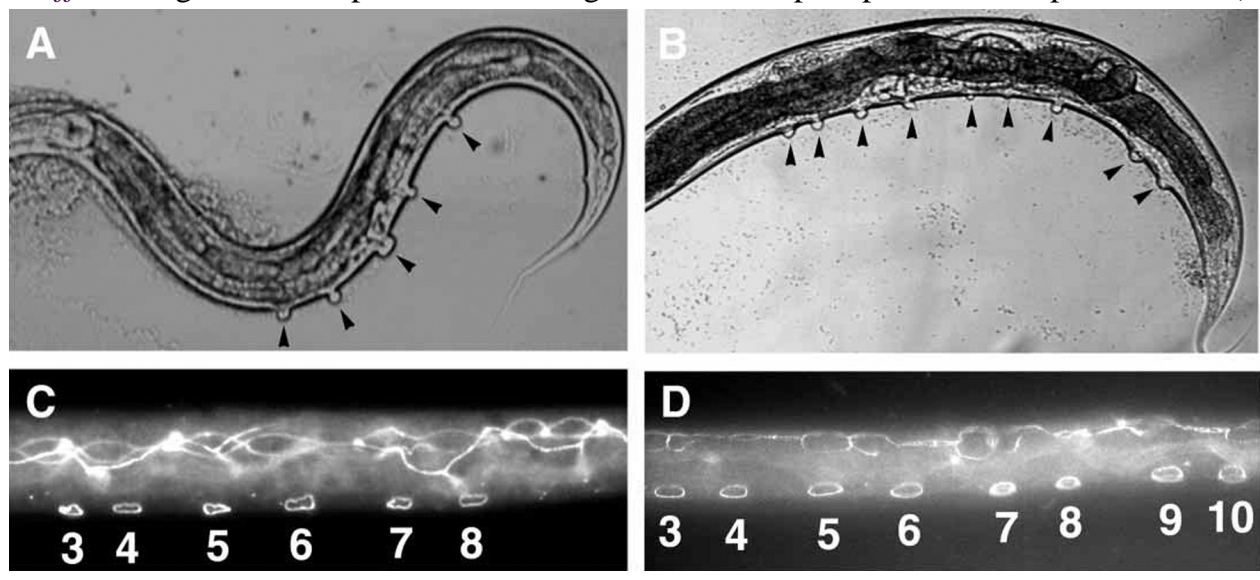

Figure 7. Posterior Pn.p remain unfused inappropriately in ref-1(mu220) mutants. (A, B) Unfused Pn.p cells are inferred from the presence of pseudovulval-like structures (indicated by black arrowheads) on the ventral surface of the worm on a lin-12(n137) background. lin-12(n137) hermaphrodites (A) usually contain five and no more than six pseudovulvae. ref-1(mu220); lin-12(n137) hermaphrodites frequently have extra pseudovulvae in the posterior body region (B). (C, D) Unfused Pn.p cells visualized by immunostaining animals with the MH27 monoclonal antibody. Wild-type worms have six unfused cells (P(3-8).p) (C) while ref-1(mu220) worms often have extra unfused cells in the posterior (P(3-10).p unfused in this picture; D). Reproduced from Alper and Kenyon (2001), Copyright (2001), with permission from The Company of Biologists.

In males, lin-39 and mab-5 proteins inhibit each other even when one of the Hox proteins is ectopically over-expressed relative to the other (Salser et al., 1993). Alper and Kenyon hypothesized that both Hox proteins may bind to regulatory sites in a cell fusion gene encoding a direct effector of cell fusion (Alper and Kenyon, 2002). In their model, the binding of either Hox protein alone would inhibit expression of a fusion gene and expression of both Hox proteins would promote expression of a fusogen resulting in Pn.p cell fusion. Alternatively, the two Hox proteins together could repress a cell fusion inhibitor (ref-2; REgulator of Fusion-2) required to prevent expression of a cell fusion gene promoting cell fusion (Figure 8; Alper and Kenyon, 2002). To investigate this complex sex-specific regulation of Pn.p cell fusion, the dominant ref-2 (mu218) mutation was isolated and cloned (Figure 9A; Alper and Kenyon, 2002). ref-2 encodes a Zn-finger protein of the odd-paired (opa)/Zic family and is required to generate Pn.p cells and to keep them unfused both in males and hermaphrodites. ref-2 is necessary, but not sufficient, to maintain Pn.p cells unfused. In addition, an active Hox gene is also necessary to prevent fusion (Figure 8-Figure 10). 
$\mathbf{A}$

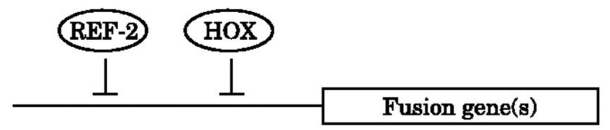

B
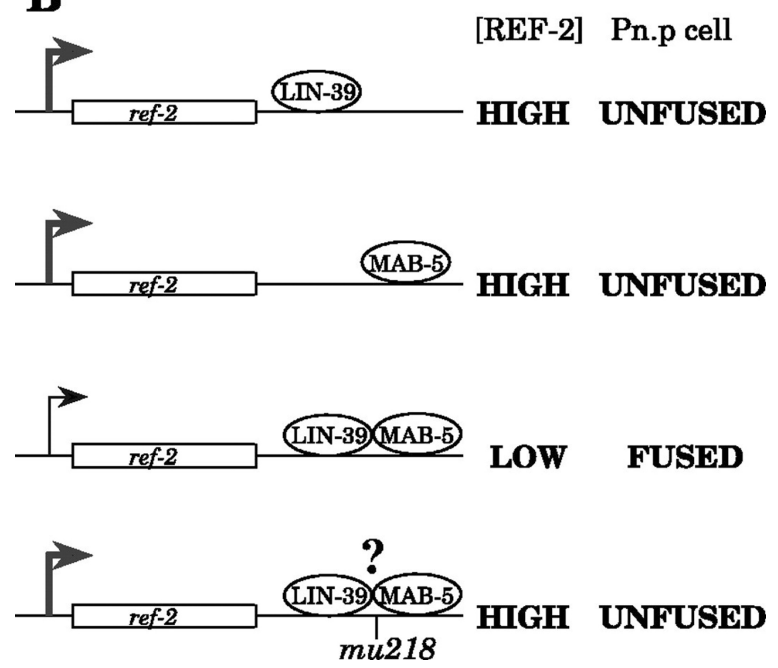

Figure 8. Two stages in ref-2-dependent patterning of Pn.p cell fusion. (A) A model for how REF-2 prevents Pn.p cell fusion. REF-2 and a Hox protein (LIN-39 or MAB-5) act by cooperatively inhibiting a common set of fusion gene targets. Alternatively, the two transcription factors could together activate a gene(s) required to prevent cell fusion. (B) A model for how ref-2 expression might be regulated. In Pn.p cells in males, either Hox protein alone (LIN-39 or MAB-5) can activate ref-2 transcription and thus can keep the concentration of REF-2 high in the Pn.p cells when the cell fusion decision is made. However, when both Hox proteins are present, ref-2 expression decreases in the Pn.p cells and those cells fuse with hyp7. The mu 218 mutation allows ref-2 to be expressed even in cells containing both LIN-39 and MAB-5 (mu218 could affect the ability of Hox proteins to bind ref-2 regulatory sites). Reproduced from Alper and Kenyon (2002), Copyright (2002), with permission from The Company of Biologists.

$\mathbf{A}$

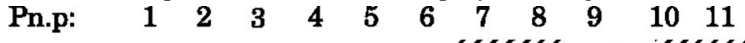

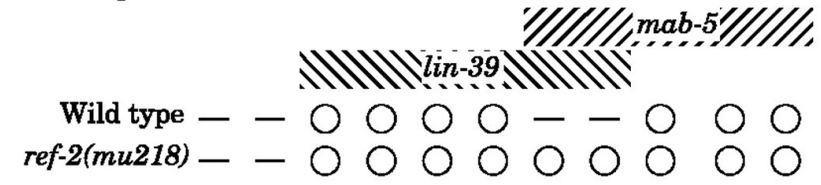

B

AIIIIIIin-39-1IIIII

$m a b-5(-)--000000--$ $m a b-5(-) ; r e f-2(m u 218)--000000-\ldots$

$\mathbf{C}$

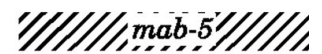

lin-39(-) - - - - - 00000

lin-39(-); ref-2(mu218) $-+-\ldots+-00000$

D

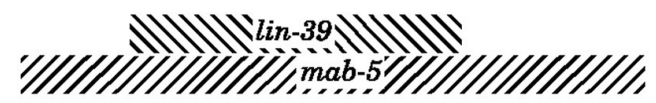

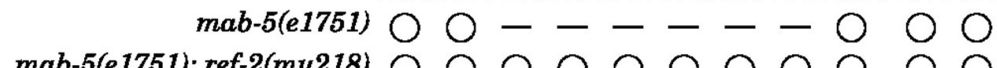

Figure 9. The ref-2(mu218) mutation prevents LIN-39 and MAB-5 from canceling each other's activities in males. The indicated mutants were stained with MH27 in early L2 to score Pn.p cell fusion in males. White circles indicate unfused Pn.p cells, short horizontal lines indicate Pn.p cells that have fused with hyp7. Hox gene expression patterns in each set of Hox mutant strains are indicated above each set of genotypes. Alleles used: lin-39(n1760) and mab-5(e2088), both null mutations, and mab-5(e1751), in which wild-type mab-5 is misexpressed in all Pn.p cells. All strains also harbored the him-5(e1490) mutation to generate males. At least 50 worms of each genotype were scored. All phenotypes listed are $100 \%$ penetrant except for: in mab-5(e1751); him-5(e1490) worms, P1.p fused with hyp7 in 1/52 worms and P3.p remained unfused in 1/52 worms, and in mab-5(e1751); him-5(e1490); ref-2(mu218) worms, P6.p fused with hyp7 in 1/51 worms. Reproduced from Alper and Kenyon (2002), Copyright (2002), with permission from The Company of Biologists. 


\section{Pn.p: $\quad \begin{array}{lllllllllll}1 & 2 & 3 & 4 & 5 & 6 & 7 & 8 & 9 & 10 & 11\end{array}$ $\begin{array}{rcccccccccccc}\text { Wild type } & - & - & \bigcirc & \bigcirc & \bigcirc & \bigcirc & \bigcirc & \bigcirc & - & - & - \\ \text { Weak ref-2(RNAi) } & - & - & - & - & - & - & - & - & - & - & - \\ \text { Strong } r e f-2(R N A i) & \text { A } & \text { A } & \text { A } & \text { A } & \text { A } & \text { A } & \text { A } & \text { A } & \text { A } & \text { A } & \text { A }\end{array}$}

Figure 10. Wild-type ref-2 is required for Pn.p cells to be generated and to remain unfused. $r e f-2$ gene function was inhibited by RNAi. A range of phenotypes was observed depending on the concentration of dsRNA injected. Weaker RNAi produced worms in which most of the Pn.p cells had fused (short horizontal lines), Stronger RNAi produced worms in which most of the Pn.p cells were absent from the ventral cord (A). White circles indicate unfused Pn.p cells. Pictured are data for hermaphrodites; similar phenotypes were also observed in males. Reproduced from Alper and Kenyon (2002), Copyright (2002), with permission from The Company of Biologists.

In summary, either mab-5 or lin-39 act with ref-2 to inhibit Pn.p cell fusion in males. When mab-5 and lin-39 are both active, fusion of Pn.p cells is not inhibited, perhaps due to low ref-2 expression. In hermaphrodites, egl-27 and $r e f-1$ prevent $m a b-5$ from affecting Pn.p cell fusion and they may act by preventing mab-5 activity on $r e f-2$ expression. It appears that eff- 1 is the ultimate effector of cell fusion in the ventral epidermis whose complex expression must be finely regulated through Hox, ref-1, ref-2 and other interacting genes in both sexes (Figure 8).

\subsubsection{L2-L4 cell fusion regulation by GATA factors and interactions with lin-39}

ELT-5/EGL-18 and ELT-6 GATA factors repress cell fusion in the VPCs (Figure 11; Koh et al., 2004; Koh et al., 2002). The cell fusion repression in the ventral epidermis appears to be controlled by lin-39/ceh-20 heterodimers binding to two HOX/PBC sites in a vulval enhancer of egl-18/elt-6. Thus EGL-18/ELT-5 and ELT-6 are genetically redundant regulators of cell fusion in the vulva primordium and may be direct targets of lin-39 (Koh et al., 2002). Moreover, reduction of lin-39 activity resulted in lower elt-6::GFP expression and over-expression of egl-18 is sufficient to partially rescue vulval defects in lin-39 (RNAi), consistent with the model in which egl-18/elt-5 and elt-6 act downstream of lin-39. It has been proposed that these GATA factors repress genes that promote Pn.p cell fusion, such as eff- 1 (Koh et al., 2004; Koh et al., 2002; see below) and also promote cell proliferation (Koh et al., 2004). One speculation is that EGL-18 and ELT-5 may also act in desilencing of condensed chromatin in the developing vulva (Koh et al., 2004). In addition, SEM-4 Zn finger transcription factor promotes vulval cell fates through lin-39 (Eisenmann and Kim, 2000; Grant et al., 2000).

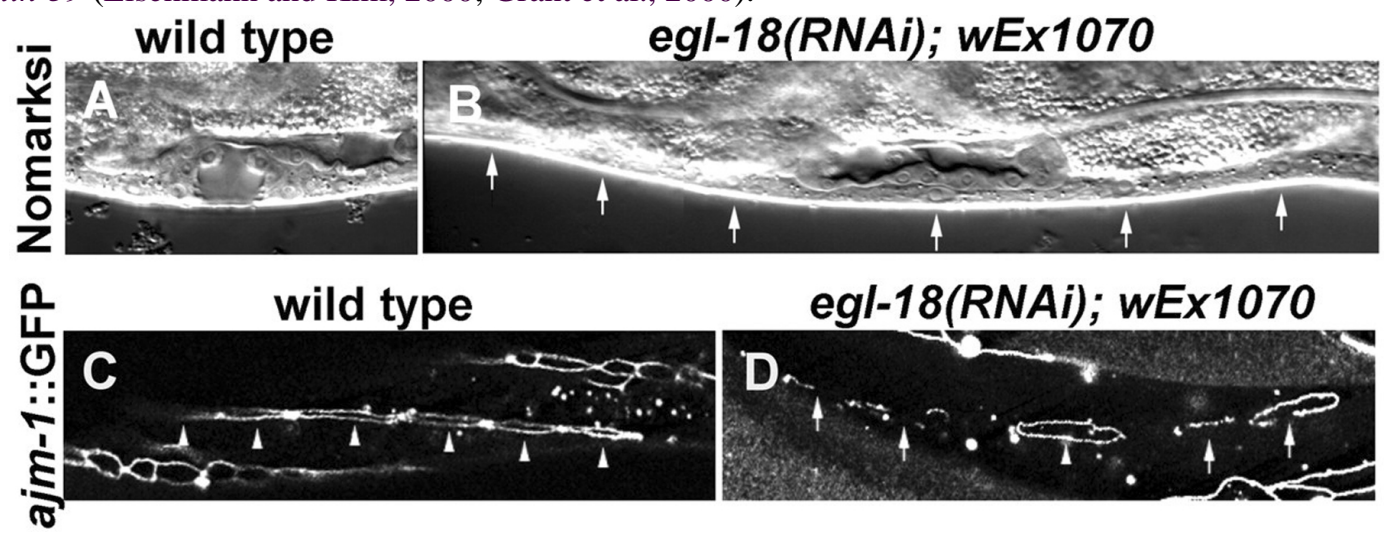

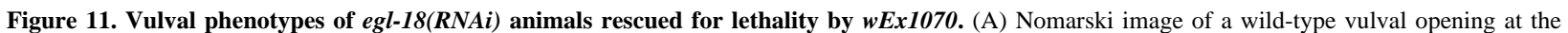
'Christmas tree' (L4) stage. (B) Nomarski image of an egl-18(RNAi); wEx1070 animal, in which all of the six P3.p-P8.p cells (arrows) did not divide and appear to have fused. (C) ajm-1::GFP (adherens junction marker) expression in a wild-type animal at the early L3 stage. All six VPCs (arrowheads) are clearly demarcated by ajm-1::GFP. One of the VPCs is partially out of focus in this image. (D) ajm-1::GFP expression in an egl-18(RNAi); wEx 1070 animal at a similar stage to the animal shown in C. All but one VPC are in the process of fusion as indicated by fragmented ajm-1::GFP expression (arrows). One VPC remains unfused as shown by a complete ring (arrowhead). Reproduced from Koh et al. (2002), Copyright (2002), with permission from The Company of Biologists.

\subsubsection{Do lin-35/Rb, lin-15 and other SynMuv genes promote hyp7-VPCs cell fusion?}

SynMuv genes and in particular $\mathrm{Rb} / \mathrm{E} 2 \mathrm{~F}$ and $\mathrm{NuRD}$ (nucleosome remodeling and histone deacetylation) complexes regulate lin-39 expression and related activities during Pn.p fusion, competence and inductions (Ch'ng and Kenyon, 1999; Chen and Han, 2001; Chen and Han, 2001; Herman et al., 1999; Solari and Ahringer, 2000; Solari et al., 1999). While the NuRD complex negatively regulates lin-39 activity, $\mathrm{Rb} / \mathrm{E} 2 \mathrm{~F}$ appears to have a negative role controlling lin-39 activity and a positive role regulating its expression (Chen and Han, 2001). These 
apparently complex genetic interactions may not be as a result of direct transcriptional regulation in all cases because some SynMuv genes do not function in the VPCs where lin-39 activity is expressed. In particular, mosaic analyses have shown that lin-15 (Herman and Hedgecock, 1990), lin-37 (Hedgecock and Herman, 1995) and lin-35/Rb (Myers and Greenwald, 2005) act in the hyp7 hypodermal syncytium and not in the VPCs to inhibit vulval fates. Thus, these results are inconsistent with the view that $\mathrm{Rb}, \mathrm{E} 2 \mathrm{~F}$, histone deacetylases and components of the NuRD and other chromatin remodeling complexes (Ceol and Horvitz, 2001; Ceol and Horvitz, 2004; Chen and Han, 2001; Chen and Han, 2001; Lu and Horvitz, 1998; Solari and Ahringer, 2000; Thomas et al., 2003; von Zelewsky et al., 2000) antagonize the inductive signaling pathways only by acting in the VPCs to transcriptionally repress effector genes required for vulval cell fates. lin-15, lin-35, lin-37 and probably other SynMuv genes may repress vulval fates by regulating a negative signal from hyp7 to the VPCs or by promoting cell fusion probably through activation of a cell fusion effector gene such as eff-1 (Herman and Hedgecock, 1990; Myers and Greenwald, 2005).

In summary, there is evidence for coordinated and complex regulation of lin-39 in the ventral epidermis by Ras, Wnt and SynMuv pathways (Chen and Han, 2001; Eisenmann et al., 1998; Fay and Han, 2000; Gleason et al., 2002; Hoier et al., 2000; Lu and Horvitz, 1998). In addition, the SEM-4 transcription factor (Eisenmann and Kim, 2000; Grant et al., 2000) and GATA factors (Koh et al., 2004; Koh et al., 2002) regulate lin-39. Overall, there appears to be several signaling pathways that control the ability of each of the ventral epidermal cells to fuse, or not to fuse, to hyp7.

\subsection{Lateral cell fusions}

Lateral seam cells actively participate in embryonic elongation but do not fuse in the wild-type embryo. However, during postembryonic development the ectoblastic seams have dynamic cell behaviors essential for the growth of hyp7 by cell fusion, generation of neurons, molting and larval elongation (Hedgecock and White, 1985; Podbilewicz and White, 1994; Singh and Sulston, 1978; Sulston and Horvitz, 1977).

\subsection{1. ceh-16/engrailed represses lateral cell fusion in the embryo}

It has recently been shown that ceh-16/engrailed is expressed in the lateral seam cells during embryonic development and induces the expression of seam cell markers including ELT-5 (Cassata et al., 2005). In contrast, ceh-16 represses eff- 1 expression in the seam cells preventing these cells from fusing (Figure 12).

In ceh-16 mutants and ceh-16 (RNAi) worms, eff- 1 is ectopically expressed in the seam cells resulting in cell fusion, morphogenesis block and embryonic lethality (Figure 13). In addition, ceh-16 mutant seam cells migrate dorsally or ventrally losing their lateral position. Animals expressing ceh-16 in some but not all seam cells in eff-1(-) background had a complete fusion failure suggesting that eff-1 acts downstream of ceh-16 (Figure 13). Thus, ceh-16 appears to maintain embryonic epidermal compartments by preventing cell fusion and maintaining the lateral seam cell borders that separate the dorsal and ventral hypodermal compartments during embryogenesis (Figure 12D; Cassata et al., 2005). 


\section{A}

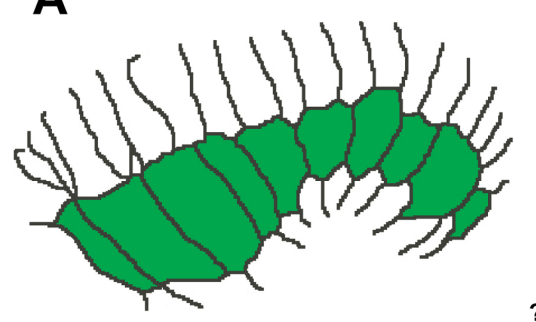

B

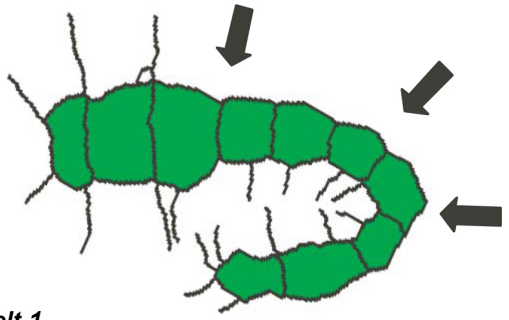

C

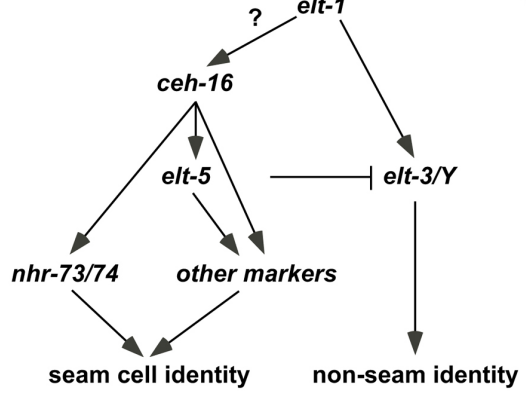

D
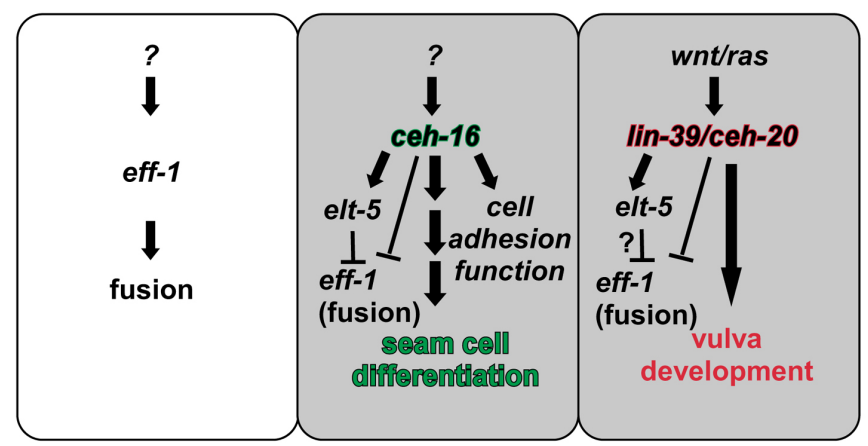

DORSAL

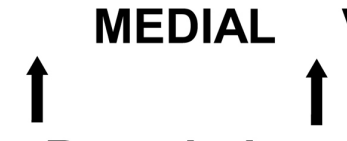

\section{Boundaries}

Figure 12. Model for the function of ceh-16/engrailed in C. elegans . (A) ceh-16/engrailed keeps the seam cells in a linear organization (green), due to its repression of seam cell fusion and cell migrations. (B) During elongation, hyp7 (dorsal) start to fuse; ceh-16/engrailed acts as a fusion repressor and as a regulator of seam-cell differentiation in order to maintain a straight boundary. At this stage genes important for "seam-cell-ness" are turned on/regulated by ceh-16/engrailed. (C) Transcriptional cascade regulating seam cell fate. (D) Summary of genetic regulatory cascades in the three rows of epidermal cells: Dorsal: eff- 1 is expressed and required for the fusion of hyp7 into a syncytium preceding and during 1.5 fold stage. It is not known which genes regulate eff-1 expression in the dorsal epidermis. Medial or Lateral: in the seam cells ceh-16/engrailed represses the expression of eff-1 (not known if directly) preceding and during 1.5 fold stage. This is necessary to allow ceh-16/engrailed to turn on genes required for correct positioning of the seam cells (cell adhesion molecules) and for the differentiation of the seam cells (elt-5 etc.). Genes that regulate ceh-16/engrailed in C. elegans are unknown. Ventral: similar to ceh-16/engrailed in the seam cells, lin-39/HoxD4/Dfd and ceh-20/Exd are required for the regulation of elt-5 and for the repression of eff-1 to allow vulva formation. During postembryonic development the seam cells act as a belt with two straight boundaries that are lost in the absence of ceh-16/engrailed. Reproduced from Cassata et al. (2005), Copyright (2005), with permission from The Company of Biologists. 


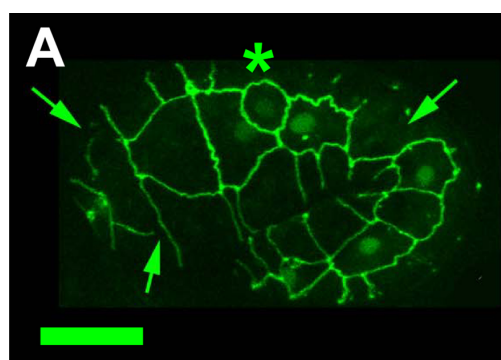

ceh-16(lg16)III; IS ajm-1::gfp; Ex ceh-16::gfp

C

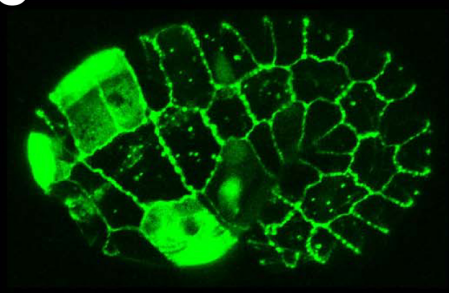

IS ajm-1::gfp; Ex eff-1p::gfp; eff-1(hy21)II

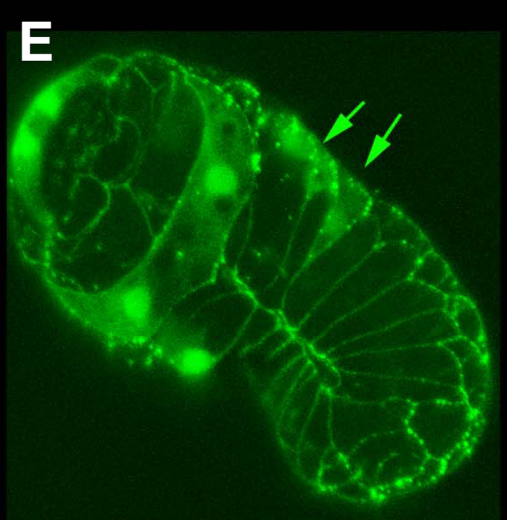

G

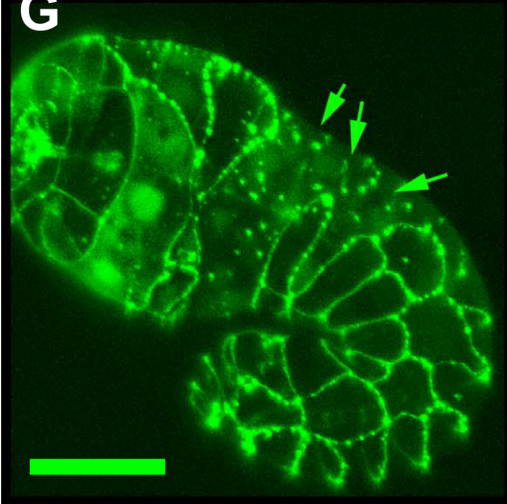

B

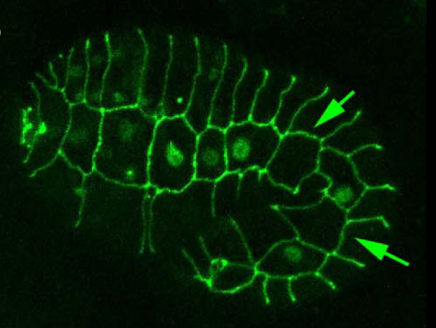

ceh-16(Ig16)III; IS ajm-1::gfp; eff-1(hy21)Il; Ex ceh-16::gfp

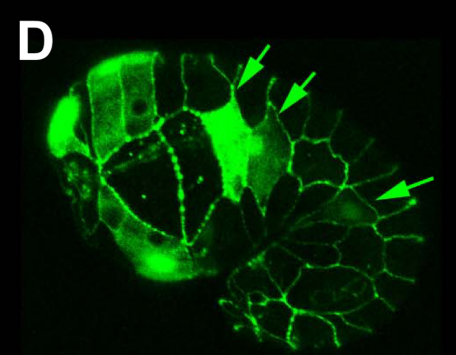

IS ajm-1::gfp; Ex eff-1p::gfp; eff-1(hy21)Il; ceh-16(RNAi)

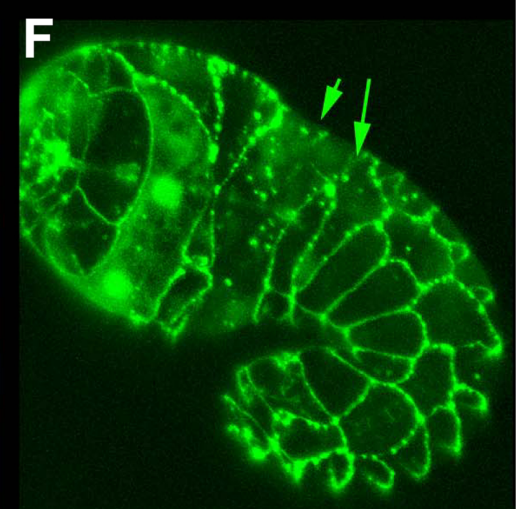

Figure 13. eff-1 expression is repressed by $c e h$-16 in the embryonic seam cells. (A) $c e h-16(\lg 16)$ mosaic for the rescue marker $c e h-16:: g f p$ shows seam cell fusions (arrows) and cell migrations (asterisk). B) Mosaic animal as in (A) crossed into eff-1(hy21); suppression of fusion (arrows). (C) eff-1(hy21) animal transgenic for an eff-1::gfp transcriptional construct that is expressed in cells committed to fuse, (D) as in (C) but in addition this animal is ceh-16(RNAi). Ectopic eff-1::gfp expression (de-repression) in the seam cells (arrows) as a result of ceh-16 inactivation and ectopic migration. (E-G) ceh-16(RNAi) embryo transgenic for eff-1::gfp taken at three time points: de-repression of eff- 1 expression in seam cells. Seam cells in which eff-1 (expression of eff-1p::gfp) is de-repressed fuse (arrows). All embryos are transgenic for ajm-1::gfp. All animals are 1.5 -fold stage except for (E) = bean stage. Scale bars: $10 \mu \mathrm{m}$. Reproduced from Cassata et al. (2005), Copyright (2005), with permission from The Company of Biologists. 


\subsubsection{ELT-5 and ELT-6 repress lateral cell fusion in the embryo and larvae}

Two GATA factors, ELT-5/EGL-18 and ELT-6 (see above), are critical for the differentiation and repression of cell fusion of the lateral seam cells (Figure 14; Koh and Rothman, 2001). Since in elt-5 (RNAi) animals the seam cells migrate and fuse ectopically (Koh and Rothman, 2001), ceh-16 may act indirectly by activating elt-5, which in turn represses eff-1. This is supported by inappropriate expression of eff-1 p::gfp in elt-5 (RNAi) embryos (Figure 15; Cassata et al., 2005). Since elt-5/elt-6 and ceh-16 are necessary to maintain the identity of the seam cells, the repression of eff-1-mediated cell fusion is probably only one of the functions of these transcription factors (Figure 12).

wild type
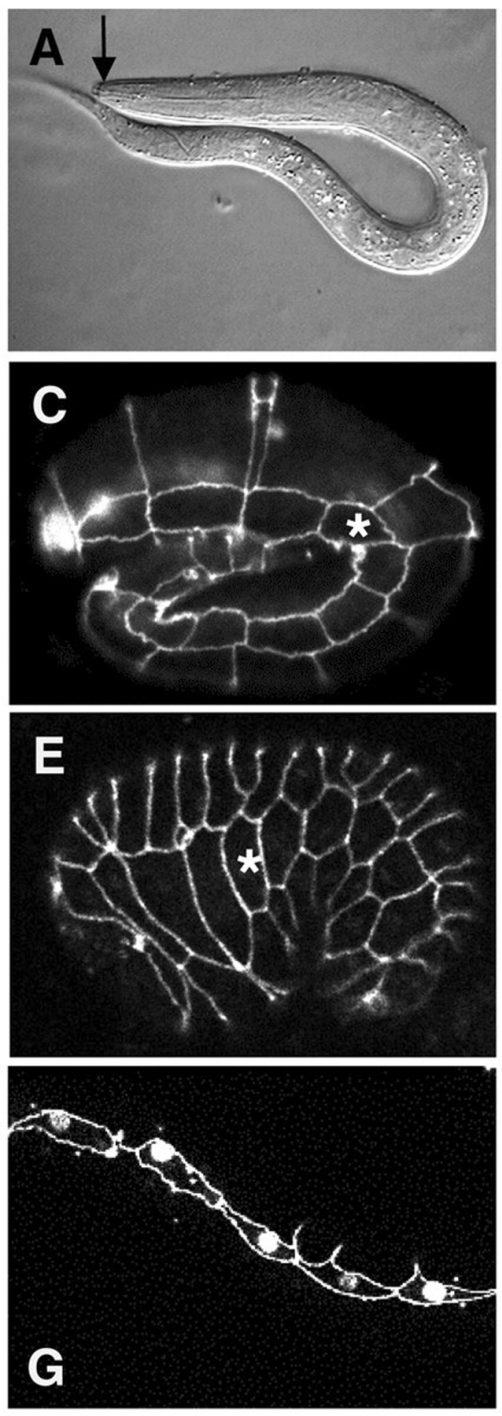

elt-5(RNAi)
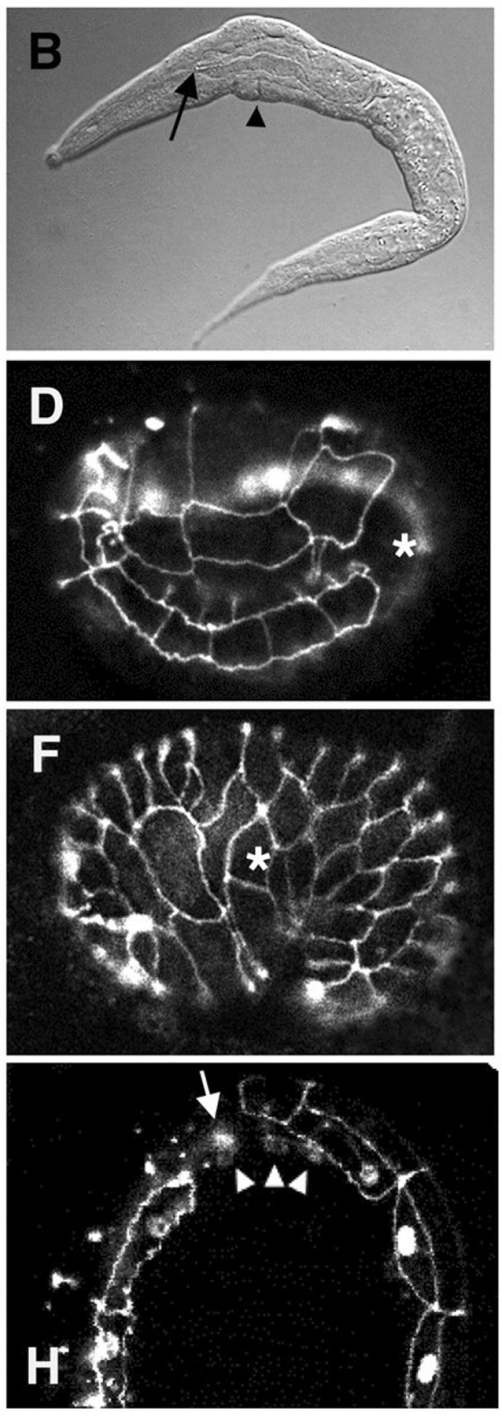

Figure 14. Phenotypes of elt-5(RNAi) embryos and larvae. (A,C, E, G) Wild-type; (B, D, F, H) elt-5(RNAi) animals. (A) Nomarski image of wild-type L1 larva. Arrow points to the buccal capsule, which is attached to the anterior end of the worm. (B) elt-5(RNAi) L1 larva showing lumps (arrowhead) and a detached buccal capsule (arrow) at the anterior end of the pharynx, which has contracted toward the posterior. (C-F) Embryos stained with mAb MH27 to visualize adherens junctions of epidermal cells. The asterisks mark the V1 seam cell. (C) Lateral view of a wild-type embryo at the 2.5-fold stage. The row of 10 lateral seam cells, all completely surrounded by adherens junctions, is prominently visible. (D) Lateral view of an elt-5(RNAi) embryo at the 2.5 -fold stage. One of the seam cells, V1 (asterisk), does not show adherens junctions, indicating that it has fused with the neighboring hyp7 syncytium on the dorsal and ventral sides. (E) Lateral view of a wild-type embryo slightly past the comma stage. All ten seam cells are visible, although part of the most posterior seam cell, $\mathrm{T}$, is out of focus. (F) Lateral view of an elt-5(RNAi) embryo slightly past the comma stage. One of the seam cells, V1 (asterisk), is ventrally misplaced, and its neighbors, H2 and V2, inappropriately contact each other. (G, H) L1-stage larvae expressing the seam cell marker SCM (nuclear signal) and AJM-1::GFP, a maker for adherens junctions. (G) Wild-type larva showing SCM expression in seam cells only. (H) elt-5(RNAi) larva showing SCM expression in nuclei of syncytial cells (arrowheads) near a fused seam cell (arrow). Reproduced from Koh and Rothman (2001), Copyright (2002), with permission from The Company of Biologists. 


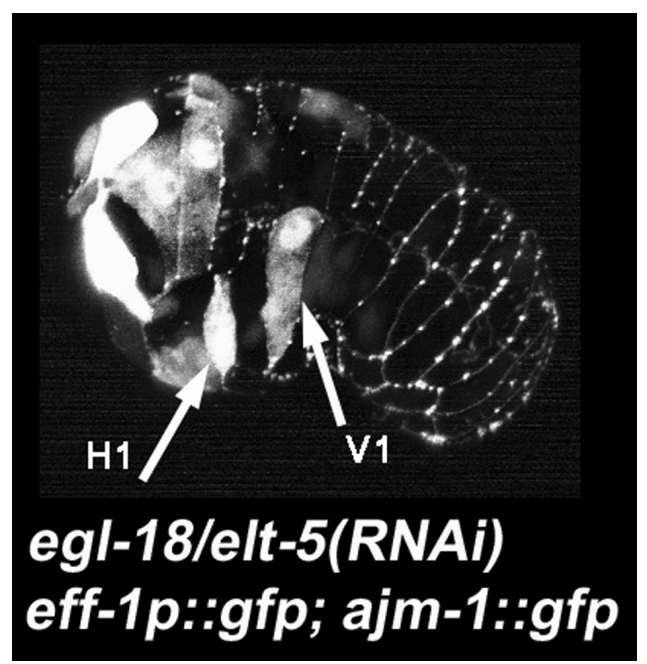

Figure 15. elt-5/egl-18 represses eff-1 expression. The arrows show two seam cells (H1 and V1) abnormally expressing eff-1p::gfp. Micrograph kindly provided by Gidi Shemer (Cassata et al., 2005).

Interestingly, cell fusion is also repressed in the ventral region of the epidermis by expression of other homeobox containing proteins lin-39/Dfd and ceh-20/Exd (Shemer and Podbilewicz, 2002) acting also through ELT-5 (Koh et al., 2002; see above). Thus, expression of distinct homeobox containing proteins in lateral and ventral hypodermal compartments may regulate cell fates through ELT-5-mediated repression of eff-1 during embryonic and larval development (Figure 12D). While Wnt and Ras signaling pathways control the expression of lin-39 in VPCs (Eisenmann and Kim, 2000; Eisenmann et al., 1998; Gleason et al., 2002; Maloof and Kenyon, 1998), it is not known what signaling pathways control ceh-16 activity in the seam cells (Cassata et al., 2005). Very few effectors of Hox genes and engrailed have been identified in any organism. In C. elegans, a putative cell fusion protein (eff-1) is a strong candidate to be an effector of ELT-5/6, lin-39-ceh-20/Extradenticle and ceh-16/engrailed in distinct developmental regions and times (Cassata et al., 2005; Shemer and Podbilewicz, 2002).

\subsubsection{Micro RNAs and regulation of the timing of postembryonic cell fusion}

The timing of larval development is regulated by the expression of micro RNAs (Ambros, 2004; See $C$. elegans microRNAs). Expression of the lin-4 micro RNA during the L1 is required for down-regulation of other heterochronic genes (e.g. lin-14) and execution of L2 developmental programs (Ambros and Horvitz, 1987; Lee et al., 1993). Likewise, expression of the let-7 micro RNA during the L4 controls the levels of other heterochronic genes (e.g. lin-29) required for adult developmental programs (Reinhart et al., 2000). Mutations in heterochronic genes result in precocious or retarded phenotypes that affect the timing of cell fusion events throughout larval development. lin-29 controls late fusion events in the L4 larvae, including the fusion between seam cells during the last molt (Ambros, 1989; Ambros and Horvitz, 1984; Slack and Ruvkun, 1997). lin-29 regulates the timing of late gene expression during organogenesis of the lateral epidermis, vulva, uterus and male reproductive system (Bettinger et al., 1997; Bettinger et al., 1996; Euling et al., 1999; Newman et al., 2000; Rougvie and Ambros, 1995). lin-29 activities are required for seam cells-vulval-uterine connections involving cell fusion events in the three interacting organs (Newman et al., 2000). Thus, lin-29 controls cell cycle exit, secretion of adult cuticle and cell fusion. It is not known whether eff-l is an effector of lin-29 and the heterochronic pathway.

\subsection{Dorsal cell fusions}

Dorsal hypodermal cells fuse during embryogenesis and most of the dorsal cells complete the fusion process halfway through morphogenesis. Very few genes controlling dorsal cell fusions have been identified. The Hox gene ceh-13 controls the embryonic fusion of some anterior dorsal hypodermal cells (Brunschwig et al., 1999; Wittmann et al., 1997) and the Hox cofactor $n h r-25$ (see above) may also affect the most anterior dorsal cell fusion in hyp7 (Chen et al., 2004).

$i d f-1$ (zu316), an embryonic lethal mutation isolated in a screen for elongation defective embryos (M. Costa and J. Priess, personal communication), is characterized by a block in embryonic dorsal cell fusion. While the idf- 1 (Irregular Dorsal Fusion-1) phenotype is variable, all the dorsal cells can fail to fuse. Irregular cell fusion events occurring in $i d f-1$ mutants are retarded compared to wild-type. The anterior dorsal cells have a higher probability of 
remaining unfused than posterior cells. However, all dorsal cells are able to remain unfused in the mutant, suggesting that $i d f-1$ is required as part of the fusion machinery or in its regulation and not only as a regional regulator of the process (T. Gattegno and BP, unpublished results; Gattegno, 1998; Gattegno, 2003; Gattegno et al., unpublished results).

\subsection{Repression of eff-1-mediated cell fusion by the vacuolar-ATPase}

fus- 1 gene protects dorsal and ventral cells from late embryonic cell fusions. In strong fus- 1 mutations (Terns et al., 1997), all epidermal cells fuse except the seam cells. eff- 1 is epistatic to fus- 1 . fus- 1 encodes a membrane e subunit of the vacuolar H+-ATPase localized to the apical membranes of epidermal fusogenic cells. Thus, eff- 1 may be mislocalized to cell membranes in the absence of V-ATPase activity and/or expression, resulting in ectopic hyperfusion (Kontani et al., 2005). The V-ATPase appears to be the first posttranscriptional repressor of eff-1-mediated cell fusion.

\subsection{Non-epidermal eff-1-independent cell fusion and the uterine-vulval connection}

The utse is a H-shaped cell that connects the uterus to the seams with a thin hymen separating the vulval and uterine lumens. This syncytium is formed in the late L4 stage by cell fusion of the AC and 8 out of $12 \pi$ daughters (Newman and Sternberg, 1996; Newman et al., 1996; Sharma-Kishore et al., 1999). The cog-2/egl-13 SOX domain and the lin-11 LIM domain transcription factors are expressed in $\pi$ cells and their daughters (Cinar et al., 2003; Hanna-Rose and Han, 1999; Newman et al., 1999). In lin-11 mutants, the AC fails to fuse with the utse and a functional uterine-vulval connection is not formed (Newman et al., 1999). In addition, lin-11 is covalently bound to SUMO (smo-1) and this modification is required for AC-utse and intratoroidal vulval fusions (Broday et al., 2004). In egl-13 mutants, the AC also fails to fuse to the utse (Cinar et al., 2003; Hanna-Rose and Han, 1999) because the $\pi$ cell lineage is initiated but not completed correctly (Cinar et al., 2003). The disruption of $\pi$ cell development is at an earlier stage in egl-13 than in lin-11 (Cinar et al., 2003). lin-11 appears to be a target of LIN-12 signaling in the $\pi$ cells (Gupta and Sternberg, 2002). Thus, both lin-11 and egl-13/cog-2 are required for the maintenance of $\pi$ cell fate and the differentiation of its progeny and not directly for cell fusion of the AC to utse. In addition, this heterotypic cell fusion event has been shown to be eff-1-independent (Shemer et al., 2004), and a NEM-sensitive factor (NSF/SEC-18) appears to be required for the AC-utse cell fusion and the formation of the uterine-vulval connection (A. Newman, personal communication).

\section{Open questions}

C. elegans has become an excellent research system to study cell membrane fusion and to understand the functions, regulation and mechanisms of cell fusion. Mutations in eff- 1 result in a complete and specific block of cell fusion without affecting other cellular functions like cell migration and adhesion. While the mechanisms of cell fusion are poorly understood, it is already clear that eff- 1 has a central role in most cell fusions in $C$. elegans. A working model is that stochastic fluctuations in the levels of eff- 1 on the plasma membranes, coupled to transcriptional and post-transcriptional mechanisms that amplify these changes, may lead to fusion of some cells where the levels of activated eff- 1 reach a threshold that triggers membrane fusion (Figure 16). A large number of regulatory genes and many more still to be discovered control the formation of a giant multinucleate cell. Most of these genes appear to precisely regulate eff- 1 transcription throughout development. It is expected that numerous posttranslational regulators of cell fusion will also act on eff- 1 stability and localization. In particular, it appears that in the worm and probably in other organisms as well, there is a widespread repression of cell membrane fusion and not only specific activation of this process. This is probably due to the negative effects of hyperfusion on viability. As occurs in program cell death in worms, ectopic activation of cell fusion results in embryonic lethality, while cell fusion failure results in sub viable larvae and adults with many morphological and behavioral defects. Many fascinating questions are completely open and waiting for a critical mass of $C$. elegans biologists interested in answering them. 


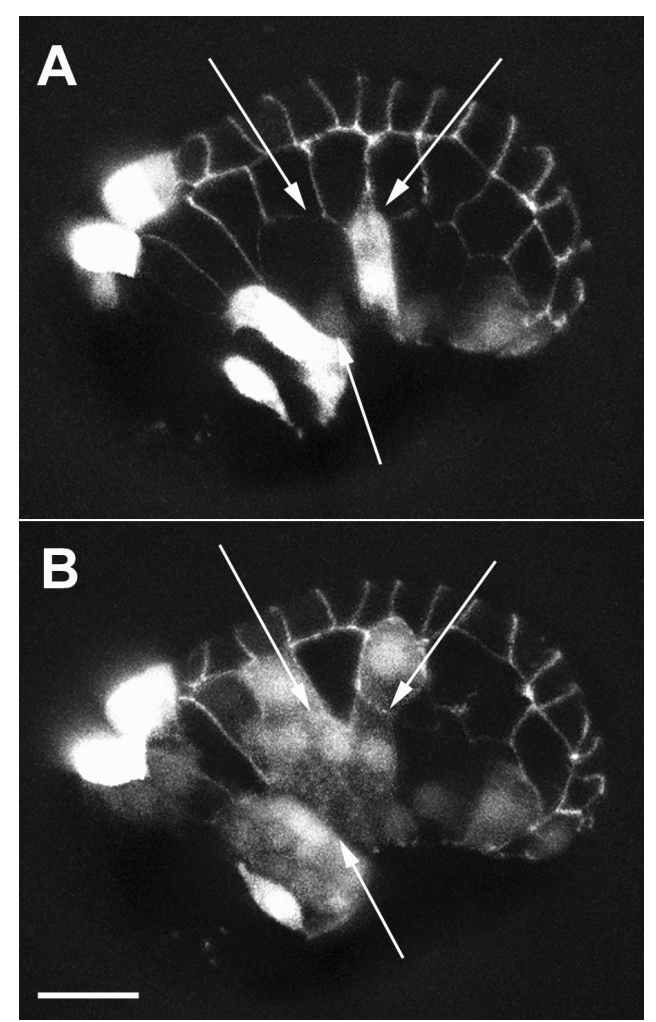

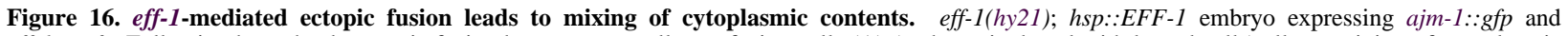
eff-1p ::gfp. Following heat shock, ectopic fusion between normally nonfusing cells (A) (embryonic dorsal with lateral cells) allows mixing of cytoplasmic contents (B). eff-1p::gfp transcriptional construct served as a cytoplasmic marker. This marker is not expressed normally in the embryonic lateral seam cells of wild-type, eff-1(-), and control animals. The cytoplasmic mixing is coupled to disappearance of apical junctions (arrows). Dorsal is up and anterior is left. The scale bar represents $10 \mu \mathrm{m}$. Reproduced from Shemer et al. (2004), Copyright (2004), with permission from Elsevier.

\subsection{Mechanistic questions}

Is there a trigger (e.g. binding, low $\mathrm{pH}$, calcium) that initiates cell fusion?

What are the intermediates and detailed kinetics of early and late fusion steps?

What is the fate of the vesicles generated during cell fusion?

How does eff- 1 affect intracellular membrane dynamics (see Figure 3 and Figure 18)?

How does eff-1 fuse cells?

What domains of the eff- 1 protein have central roles in cell fusion?

Which eff- 1 isoform(s) are essential and sufficient for cell fusion?

Is eff- 1 a fusogen similar to viral class I or II fusogens or is it a class of its own?

What is the structure of eff-1?

Is there cooperativity between different eff- 1 proteins to fuse cells?

Is eff- 1 the only effector of cell fusion in $C$. elegans?

Are there eff- 1 receptors and co receptors?

Does eff- 1 have functions independent of cell fusion?

Does eff- 1 act as an anti-cell migration factor in the epidermis (see Figure 17 and Figure 18)?

Does cell fusion have a role in larval elongation?

Are the late defects that develop after fusion failure direct or indirect?

Are there other genes required for cell attachment, pore formation, expansion of cytoplasmic bridge and rearrangement of cytoplasmic contents during cell fusion? 


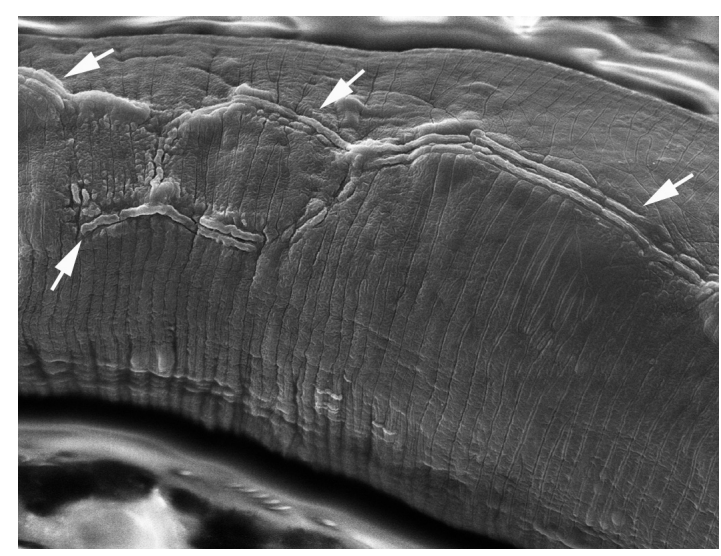

Figure 17. SEM of eff- 1 body cuticle shows defective alae. The alae are formed by the underlying seam cells, and show distinct differences at various developmental stages (singlet in L1, quartet in dauer, triplet in adult, no alae in L2, L3 or L4; D.H. Hall and R. Lints, wormatlas.org/hermaphrodite/cuticle/Cutframeset.html ). In wild type the seam cells fuse into a single midline row, whereas in eff-1 they fail to fuse and can form overlapping or parallel rows. Here in an adult eff- 1 animal, arrows indicate the malformed alae running lengthwise along the lateral body wall, generally as doublet or triplet ridges. In wild type the adult alae form one triplet ridge at the exact midline, whereas in the eff- 1 animals the alae wander and split repeatedly to form several parallel stripes. Reproduced from Shemer et al. (2004), Copyright (2004), with permission from Elsevier.

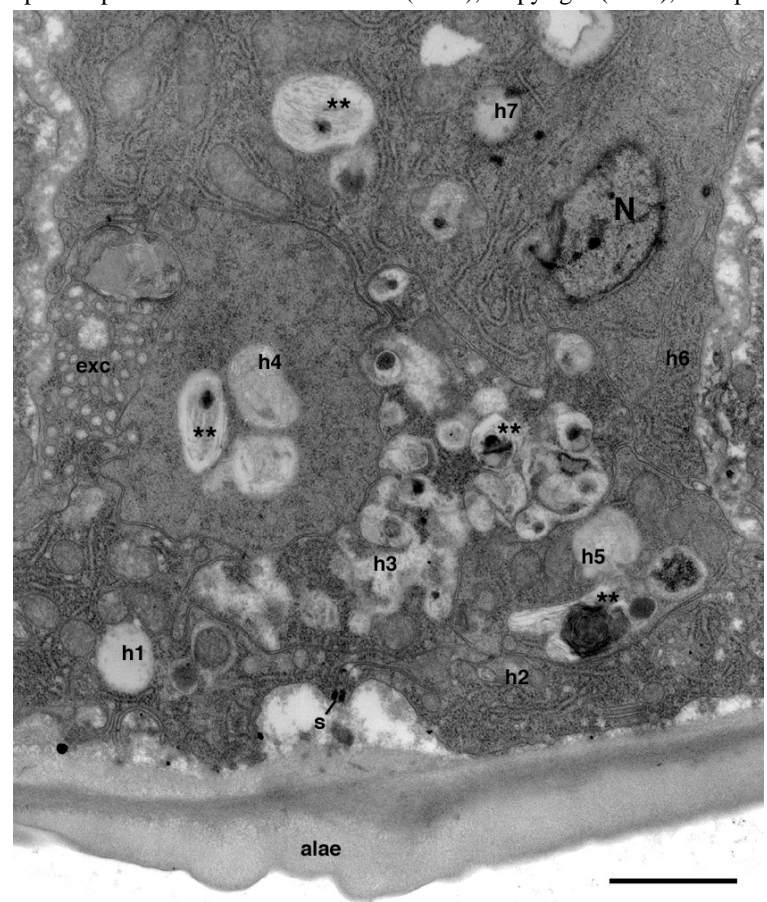

Figure 18. Autophagy and epithelial stratification in lateral hypodermal tissue. eff- 1 animal shows reduced alae formation, and fusion failure has caused hypodermal tissue to be divided by membranes into 7 separate compartments, numbered here as h1-h7, of which only h1 and h2 face the cuticle directly. Unlike normal syncytial epidermis, where each hyp compartment is exposed to the cuticle, this portion of lateral epidermis has become stratified and the interior hypodermal cells show signs of autophagy $(* *)$ (Melendez et al., 2003), perhaps due to a buildup of cuticle-related products in cells h3-h7. $\mathrm{N}$, hypodermal nucleus. exc, excretory canal. s, seam cell. Ventral is to the left, lateral side is down. Scale bar is $1 \mu \mathrm{m}$. Reproduced from Shemer et al. (2004), Copyright (2004), with permission from Elsevier.

\subsection{Regulatory questions}

eff- 1 is controlled by regulators of cell fusion (ref- 1 and ref-2), Hox genes and other cofactors in the ventral Pn.p cells and by the homeodomain gene ceh-16/engrailed and GATA factors ELT-5/EGL-18 in the lateral seam cells.

Are these regulators acting directly or indirectly on eff- 1 transcription?

Are there posttranscriptional mechanisms of regulation of eff-1?

How does a V-ATPase represses eff-1-mediated epidermal fusion? 
How does the heterochronic pathway control cell fusion?

How are dorsal hypodermal cell fusions regulated in the embryo?

\section{Implications of cell fusion research beyond worms}

Cell fusion is a very frequent and naturally occurring process about which very little is known. We are beginning to understand why cells fuse during the formation of organs in C. elegans (Figure 5). Cell fusion research has potential applications in the fields of contraception, cancer, gene therapy and stem cell research. Cell fusions in the epidermis and vulva of $C$. elegans and during the formation of muscles, bones and placenta in humans, involve regulation of cell differentiation. Dividing cells that are potentially invasive (e.g. epidermal, muscle, placenta and stem cells) fuse to form part of multinucleated cells, stop dividing, and become differentiated. Thus, defects in cell fusion during development may result in cancerous growth in mammals (Duelli and Lazebnik, 2003). However, as with apoptosis, this is not the case in worms. Finally, laser-induced cell fusion in worms (Irle and Schierenberg, 2002; Schierenberg, 1984; Schierenberg, 1987) and other organisms (Avigan et al., 2004; Lundqvist et al., 2004) is an under-explored technique with great potential for understanding many basic and applied biological questions.

\section{Acknowledgements}

I thank Scott Alper, Jim Kramer and Gidi Shemer for critically reading the manuscript. I thank past and present members of the worm community in Haifa for invaluable contributions and members of the Chernomordik lab and the worm community of Bethesda for their support. Supported by grants from the Israel Science Foundation, Fund for the Promotion of Research at the Technion and HFSP.

\section{References}

Albertson, D.G., and Thomson, J.N. (1976). The pharynx of Caenorhabditis elegans. Philos. Trans. R. Soc. Lond. B. Biol. Sci. 275, 299-325. Abstract

Alper, S., and Kenyon, C. (2001). REF-1, a protein with two bHLH domains, alters the pattern of cell fusion in $C$. elegans by regulating Hox protein activity. Development 128, 1793-1804. Abstract

Alper, S., and Kenyon, C. (2002). The zinc finger protein REF-2 functions with the Hox genes to inhibit cell fusion in the ventral epidermis of C. elegans. Development 129, 3335-3348. Abstract

Ambros, V. (1989). A hierarchy of regulatory genes controls a larva-to-adult development switch in C. elegans. Cell 57, 49-57. Abstract Article

Ambros, V. (2004). The functions of animal microRNAs. Nature 431, 350-355. Abstract Article

Ambros, V., and Horvitz, H.R. (1984). Heterochronic mutants of the nematode Caenorhabditis elegans. Science 226, 409-416. Abstract

Ambros, V., and Horvitz, H.R. (1987). The lin-14 locus of Caenorhabditis elegans controls the time of expression of specific postembryonic developmental events. Genes Dev. 1, 398-414. Abstract

Ambros, V., and Moss, E.G. (1994). Heterochronic genes and the temporal control of C. elegans development. Trends Genet. 10, 123-127. Abstract Article

Asahina, M., Ishihara, T., Jindra, M., Kohara, Y., Katsura, I., and Hirose, S. (2000). The conserved nuclear receptor Ftz-F1 is required for embryogenesis, moulting and reproduction in Caenorhabditis elegans. Genes Cells 5, 711-723. Abstract Article

Avigan, D., Vasir, B., Gong, J., Borges, V., Wu, Z., Uhl, L., Atkins, M., Mier, J., McDermott, D., Smith, T., et al. (2004). Fusion cell vaccination of patients with metastatic breast and renal cancer induces immunological and clinical responses. Clin. Cancer Res. 10, 4699-4708. Abstract Article

Baird, S.E., Fitch, D.A., Kassem, I.A.A., and Emmons, S.W. (1991). Pattern formation in the nematode epidermis: determination of the arrangement of peripheral sense organs in the C. elegans male tail. Development 113, 515-526. Abstract 
Baroux, C., Fransz, P., and Grossniklaus, U. (2004). Nuclear fusions contribute to polyploidization of the gigantic nuclei in the chalazal endosperm of Arabidopsis. Planta 220, 38-46. Abstract Article

Bettinger, J.C., Euling, S., and Rougvie, A.E. (1997). The terminal differentiation factor LIN-29 is required for proper vulval morphogenesis and egg laying in Caenorhabditis elegans. Development 124, 4333-4342. Abstract

Bettinger, J.C., Lee, K., and Rougvie, A.E. (1996). Stage-specific accumulation of the terminal differentiation factor LIN-29 during Caenorhabditis elegans development. Development 122, 2517-2527. Abstract

Broday, L., Kolotuev, I., Didier, C., Bhoumik, A., Gupta, B.J., Sternberg, P.W., Podbilewicz, B., and Ronai, Z. (2004). The small ubiquitin like modifier (SUMO) is required for gonadal and uterine-vulval morphogenesis in $C$. elegans. Genes Dev. 18, 2380-2391. Abstract Article

Brooks, D.R., Appleford, P.J., Murray, L., and Isaac, R.E. (2003). An essential role in molting and morphogenesis of Caenorhabditis elegans for ACN-1, a novel member of the angiotensin-converting enzyme family that lacks a metallopeptidase active site. J. Biol. Chem. 278, 52340-52346. Abstract Article

Brunschwig, K., Wittmann, C., Schnabel, R., Burglin, T.R., Tobler, H., and Muller, F. (1999). Anterior organization of the Caenorhabidtis elegans embryo by the labial-like Hox gene ceh-13. Development 126, 1537-1546. Abstract

Burdine, R.D., Branda, C.S., and Stern, M.J. (1998). Egl-17(fgf) expression coordinates the attraction of the migrating sex myoblasts with vulval induction in C. elegans. Development 125, 1083-1093. Abstract

Cassata, G., Shemer, G., Morandi, P., Donhauser, R., Podbilewicz, B., and Baumeister, R. (2005). ceh-16/engrailed patterns the embryonic epidermis of Caenorhabditis elegans. Development 132, 739-749. Abstract Article

Ceol, C.J., and Horvitz, H.R. (2001). dpl-1 DP and efl-1 E2F act with lin-35 Rb to antagonize Ras signaling in $C$. elegans vulval development. Mol. Cell 7, 461-473. Abstract Article

Ceol, C.J., and Horvitz, H.R. (2004). A new class of C. elegans synMuv genes implicates a Tip60/NuA4-like HAT complex as a negative regulator of Ras signaling. Dev. Cell 6, 563-576. Abstract Article

Ch'ng, Q., and Kenyon, C. (1999). egl-27 generates anteroposterior patterns of cell fusion in C. elegans by regulating Hox gene expression and Hox protein function. Development 126, 3303-3312. Abstract

Chen, E.H., and Olson, E.N. (2004). Towards a molecular pathway for myoblast fusion in Drosophila. Trends Cell Biol. 14, 452-460. Abstract Article

Chen, E.H., and Olson, E.N. (2005). Unveiling the mechanisms of cell-cell fusion. Science 308, 369-373. Abstract Article

Chen, Z., Eastburn, D.J., and Han, M. (2004). The Caenorhabditis elegans nuclear receptor gene $n h r$ - 25 regulates epidermal cell development. Mol. Cell Biol. 24, 7345-7358. Abstract Article

Chen, Z., and Han, M. (2001). C. elegans Rb, NuRD, and Ras regulate lin-39-mediated cell fusion during vulval fate specification. Curr. Biol. 11, 1874-1879. Abstract Article

Chen, Z., and Han, M. (2001). Role of C. elegans lin-40 MTA in vulval fate specification and morphogenesis. Development 128, 4911-4921. Abstract

Chisholm, A. (1991). Control of cell fate in the tail region of C. elegans by the gene egl-5. Development 111, 921-932. Abstract

Chitwood, B.G., and Chitwood, M.B.H. (1974). Introduction to nematology, Consolidated edn (Baltimore, University Park Press).

Cinar, H.N., Richards, K.L., Oommen, K.S., and Newman, A.P. (2003). The EGL-13 SOX Domain Transcription Factor Affects the Uterine $\pi$ Cell Lineages in Caenorhabditis elegans. Genetics 165, 1623-1628. Abstract 
Clandinin, T.R., Katz, W.S., and Sternberg, P.W. (1997). Caenorhabditis elegans Hom-C genes regulate the response of vulval precursor cells to inductive signal. Dev. Biol. 182, 150-161. Abstract Article

Clark, S.G., Chisholm, A.D., and Horvitz, H.R. (1993). Control of cell fates in the central body region of C. elegans by the homeobox gene lin-39. Cell 74, 43-55. Abstract Article

Cross, J.C., Werb, Z., and Fisher, S.J. (1994). Implantation and the placenta: key pieces of the development puzzle. Science 266, 1508-1518. Abstract

Cui, M., and Han, M. (2003). Cis regulatory requirements for vulval cell-specific expression of the Caenorhabditis elegans fibroblast growth factor gene egl-17. Dev. Biol. 257, 104-116. Abstract Article

del Campo, J.J., Opoku-Serebuoh, E., Isaacson, A.B., Scranton, V.L., Tucker, M., Han, M., and Mohler, W.A. (2005). Fusogenic activity of EFF-1 is regulated via dynamic localization in fusing somatic cells of C. elegans. Curr. Biol. 15, 413-423. Abstract Article

Ding, M., Woo, W.M., and Chisholm, A.D. (2004). The cytoskeleton and epidermal morphogenesis in C. elegans. Exp. Cell Res. 301, 84-90. Abstract Article

Duelli, D., and Lazebnik, Y. (2003). Cell fusion: a hidden enemy? Cancer Cell 3, 445-448. Abstract Article

Earp, L.J., Delos, S.E., Park, H.E., and White, J.M. (2005). The many mechanisms of viral membrane fusion proteins. Curr. Top Microbiol. Immunol. 285, 25-66. Abstract

Eisenmann, D.M., and Kim, S.K. (2000). Protruding-vulva mutants identify novel loci and Wnt signaling factors that function during Caenorhabditis elegans vulval development. Genetics 156, 1097-1116. Abstract

Eisenmann, D.M., Maloof, J.N., Simske, J.S., Kenyon, C., and Kim, S.K. (1998). The b-catenin homolog BAR-1 and LET-60 ras coordinately regulate the hox gene lin-39 during Caenorhabditis elegans vulval development. Development 125, 3667-3680. Abstract

Emmons, S., and Sternberg, P. (1997). Male development and mating behavior. In C. elegans I, D. Riddle, T. Blumenthal, B. Meyer, and J. Priess, eds. (Cold Spring Harbor, Cold Spring Harbor Laboratory Press), pp. 295-334.

Euling, S., Bettinger, J., and Rougvie, A.E. (1999). The lin-29 transcription factor is required for proper morphogenesis of the Caenorhabditis elegans male tail. Dev. Biol. 206, 142-156. Abstract Article

Fay, D.S., and Han, M. (2000). The synthetic multivulval genes of C. elegans: functional redundency, ras-antagonism, and cell fate determination. Genesis 26, 279-284. Abstract Article

Fitch, D.H.A. (1997). Evolution of male tail development in Rhabditid nematodes related to Caenorhabditis elegans. Syst. Biol. 46, 145-179. Abstract

Francis, G.R., and Waterston, R.H. (1991). Muscle cell attachment in Caenorhabditis elegans. J. Cell Biol. 114, 465-479. Abstract Article

Gattegno, T. (1998). Cell fusion in the nematode C. elegans, characterization of a mutant with defects in the fusion processes. M Sc. Abstract

Gattegno, T. (2003) Isolation and characterization of cell fusion mutants in C. elegans, Ph.D., Technion-Israel Institute of Technology, Haifa.

Gissendanner, C.R., and Sluder, A.E. (2000). nhr-25, the Caenorhabditis elegans ortholog of ftz-f1, is required for epidermal and somatic gonad development. Dev. Biol. 221, 259-272. Abstract Article

Gleason, J.E., Korswagen, H.C., and Eisenmann, D.M. (2002). Activation of Wnt signaling bypasses the requirement for RTK/Ras signaling during C. elegans vulval induction. Genes Dev. 16, 1281-1290. Abstract Article

Grant, K., Hanna-Rose, W., and Han, M. (2000). sem-4 promotes vulval cell-fate determination in Caenorhabidtis elegans through regulation of lin-39 Hox. Dev. Biol. 224, 496-506. Abstract Article 
Greenwald, I. (1997). Development of the vulva. In C. elegans II, D.L. Riddle, T. Blumenthal, B.J. Meyer, and J.R. Priess, eds. (Cold Spring Harbor, Cold Spring Harbor Laboratory Press), pp. 519-541.

Gupta, B.P., and Sternberg, P.W. (2002). Tissue-specific regulation of the LIM homeobox gene lin-11 during development of the Caenorhabditis elegans egg-laying system. Dev. Biol. 247, 102-115. Abstract Article

Gutierrez, A., Knoch, L., Witte, H., and Sommer, R.J. (2003). Functional specificity of the nematode Hox gene mab-5. Development 130, 983-993. Abstract Article

Hanna-Rose, W., and Han, M. (1999). COG-2, a Sox domain protein necessary for establishing a functional vulval-uterine connection in Caenorhabditis elegans. Development 126, 169-179. Abstract

Hedgecock, E.M., and Herman, R.K. (1995). The ncl-1 gene and genetic mosaics of Caenorhabditis elegans. Genetics 141, 989-1006. Abstract

Hedgecock, E.M., and White, J.G. (1985). Polyploid tissues in the nematode Caenorhabditis elegans. Dev. Biol. 107, 128-138. Abstract Article

Heiman, M.G., and Walter, P. (2000). Prm1p, a pheromone-regulated multispanning membrane protein, facilitates plasma membrane fusion during yeast mating. J. Cell Biol. 151, 719-730. Abstract Article

Herman, M.A., Ch'ng, Q., Hettenbach, S.M., Ratliff, T.M., Kenyon, C., and Herman, R.K. (1999). EGL-27 is similar to a metastasis-associated factor and controls cell polarity and cell migration in C. elegans. Development 126 , 1055-1064. Abstract

Herman, R.K., and Hedgecock, E.M. (1990). Limitations of the size of the vulval primordium of Caenorhabditis elegans by lin-15 expression in surrounding hyopodermis. Nature 348, 169-171. Abstract Article

Hickey, P.C., Jacobson, D., Read, N.D., and Louise Glass, N.L. (2002). Live-cell imaging of vegetative hyphal fusion in Neurospora crassa. Fungal Genet. Biol. 37, 109-119. Abstract Article

Hoier, E.F., Mohler, W.A., Kim, S.K., and Hajnal, A. (2000). The Caenorhabidtis elegans APC-related gene apr-1 is required for epithelial cell migration and Hox gene expression. Genes Dev. 14, 874-886. Abstract

Irle, T., and Schierenberg, E. (2002). Developmental potential of fused Caenorhabditis elegans oocytes: generation of giant and twin embryos. Dev. Genes Evol. 212, 257-266. Abstract Article

Jahn, R., Lang, T., and Sudhof, T.C. (2003). Membrane fusion. Cell 112, 519-533. Abstract Article

Jee, W.S.S., and Nolan, P.D. (1963). Origin of osteoclasts from the fusion of phagocytes. Nature 200, $225-226$. Abstract

Jungblut, B., Pires-daSilva, A., and Sommer, R.J. (2001). Formation of the egg-laying system in Pristionchus pacificus requires complex interactions between gonadal, mesodermal and epidermal tissues and does not rely on single cell inductions. Development 128, 3395-3404. Abstract

Jungblut, B., and Sommer, R.J. (1998). The Pristionchus pacificus mab-5 gene is involved in the regulation of ventral epidermal cell fates. Curr. Biol. 8, 775-778. Abstract Article

Kenyon, C. (1986). A gene involved in the development of the posterior body region of C. elegans. Cell 46, 477-487. Abstract Article

Knust, E., and Bossinger, O. (2002). Composition and formation of intercellular junctions in epithelial cells. Science 298, 1955-1959. Abstract Article

Koh, K., Bernstein, Y., and Sundaram, M.V. (2004). The $n T 1$ translocation separates vulval regulatory elements from the egl-18 and elt-6 GATA factor genes. Dev. Biol. 267, 252-263. Abstract Article 
Koh, K., Peyrot, S.M., Wood, C.G., Wagmaister, J.A., Maduro, M.F., Eisenmann, D.M., and Rothman, J.H. (2002). Cell fates and fusion in the $C$. elegans vulval primordium are regulated by the EGL-18 and the ELT-6 GATA factors- apparent direct targets of the LIN-39 Hox protein. Development 129, 5171-5180. Abstract

Koh, K., and Rothman, J.H. (2001). ELT-5 and ELT-6 are required continuously to regulate epidermal seam cell differentiation and cell fusion in C. elegans. Development 128, 2867-2880. Abstract

Kolotuev, I., and Podbilewicz, B. (2004). Pristionchus pacificus vulva formation: polarized division, cell migration, cell fusion and evolution of invagination. Dev. Biol. 266, 322-333. Abstract Article

Kontani, K., Moskowitz, I.P.G., and Rothman, J.H. (2005). Repression of cell-cell fusion by components of the $C$. elegans vacuolar ATPase complex. Dev. Cell In press. Abstract Article

Kontani, K., and Rothman, J.H. (2005). Cell Fusion: EFF Is Enough. Curr. Biol. 15, R252-254. Abstract Article

Koppen, M., Simske, J.S., Sims, P.A., Firestein, B.L., Hall, D.H., Radice, A.D., Rongo, C., and Hardin, J.D. (2001). Cooperative regulation of AJM-1 controls junctional integrity in Caenorhabditis elegans epithelia. Nat. Cell Biol. 3 , 983-991. Abstract Article

Kornfeld, K. (1997). Vulval development in Caenorhabditis elegans. Trends Genet. 13, 55-61. Abstract Article

Kuszak, J.R., Macsai, M.S., Bloom, K.J., Rae, J.L., and Weinstein, R.S. (1985). Cell-to-cell fusion of lens fiber cells in situ: correlative light, scanning electron microscopic, and freeze-fracture studies. J. Ultrastruct. Res. 93, 144-160. Abstract Article

L'Hernault, S. (1997). Spermatogenesis. In C. elegans II, D. Riddle, T. Blumenthal, B. Meyer, and J. Priess, eds. (Cold Spring Harbor, Cold Spring Harbor Laboratory Press), pp. 271-294.

Labouesse, M. (1997). Deficiency screen based on the monoclonal antibody MH27 to identify genetic loci required for morphogenesis of the Caenorhabditis elegans embryo. Dev. Dyn. 210, 19-32. Abstract Article

Lee, R.C., Feinbaum, R.L., and Ambros, V. (1993). The C. elegans heterochronic gene lin-4 encodes small RNAs with antisense complementarity to lin-14. Cell 75, 843-854. Abstract Article

Leikina, E., Mittal, A., Cho, M.S., Melikov, K., Kozlov, M.M., and Chernomordik, L.V. (2004). Influenza hemagglutinins outside of the contact zone are necessary for fusion pore expansion. J. Biol. Chem. 279, 26526-26532. Abstract Article

Liu, J., and Fire, A. (2000). Overlapping roles for two Hox genes and the exd ortholog ceh-20 in diversification of the C. elegans postembryonic mesoderm. Development 127, 5179-5190. Abstract

Louvet-Vallee, S., Kolotuev, I., Podbilewicz, B., and Felix, M.-A. (2003). Control of vulval competence and centering in the nematode Oscheius sp.1 CEW1. Genetics 163, 133-146. Abstract

Lu, X., and Horvitz, H.R. (1998). lin-35 and lin-53, two genes that antagonize a C. elegans Ras pathway, encode proteins similar to $\mathrm{Rb}$ and its binding protein RbAp48. Cell 95, 981-991. Abstract Article

Lundqvist, A., Palmborg, A., Bidla, G., Whelan, M., Pandha, H., and Pisa, P. (2004). Allogeneic tumor-dendritic cell fusion vaccines for generation of broad prostate cancer T-cell responses. Med. Oncol. 21, 155-165. Abstract Article

Maloof, J.N., and Kenyon, C. (1998). The Hox gene lin-39 is required during C. elegans vulval induction to select the outcome of Ras signaling. Development 125, 181-190. Abstract

Melendez, A., Talloczy, Z., Seaman, M., Eskelinen, E.L., Hall, D.H., and Levine, B. (2003). Autophagy genes are essential for dauer development and life-span extension in C. elegans. Science 301, 1387-1391. Abstract Article

Michaux, G., Legouis, R., and Labouesse, M. (2001). Epithelial biology: lessons from Caenorhabditis elegans. Gene 277, 83-100. Abstract Article 
Mohler, W.A. (1999). Visual reality: using computer reconstruction and animation to magnify the microscopist's perception. Mol. Biol. Cell 10, 3061-3065. Abstract

Mohler, W.A., Shemer, G., del Campo, J., Valansi, C., Opoku-Serebuoh, E., Scranton, V., Assaf, N., White, J.G., and Podbilewicz, B. (2002). The type I membrane protein EFF-1 is essential for developmental cell fusion in $C$. elegans. Dev. Cell 2, 355-362. Abstract Article

Mohler, W.A., Simske, J.S., Williams-Masson, E.M., Hardin, J.D., and White, J.G. (1998). Dynamics and ultrastructure of developmental cell fusions in the Caenorhabditis elegans hypodermis. Curr. Biol. 8, 1087-1090. Abstract Article

Mohler, W.A., and White, J.G. (1998). Stereo-4-D reconstruction and animation from living fluorescent specimens. Biotechniques 24, 1006-1010. Abstract

Myers, T.R., and Greenwald, I. (2005). lin-35 Rb Acts in the Major Hypodermis to Oppose Ras-Mediated Vulval Induction in C. elegans. Dev. Cell 8,117-123. Abstract Article

Newman, A.P., Acton, G.Z., Hartwieg, E., Horvitz, H.R., and Sternberg, P.W. (1999). The lin-11 LIM domain transcription factor is necessary for morphogenesis of C. elegansuterine cells. Development 126, 5319-5326. Abstract

Newman, A.P., Inoue, T., Wang, M.Q., and Sternberg, P.W. (2000). The Caenorhabditis elegans heterochronic gene lin-29 coordinates the vulval-uterine-epidermal connections. Curr. Biol. 10, 1479-1488. Abstract Article

Newman, A.P., and Sternberg, P.W. (1996). Coordinated morphogenesis of epithelia during development of the Caenorhabditis elegans uterine-vulval connection. Proc. Natl. Acad. Sci. USA 93, 9329-9333. Abstract Article

Newman, A.P., White, J.G., and Sternberg, P.W. (1996). Morphogenesis of the C. elegans hermaphrodite uterus. Development 122, 3617-3626. Abstract

Nguyen, C.Q., Hall, D.H., Yang, Y., and Fitch, D.H.A. (1999). Morphogenesis of the Caenorhabditis elegans male tail tip. Dev. Biol. 207, 86-106. Abstract Article

Nilsson, L., Li, X., Tiensuu, T., Auty, R., Greenwald, I., and Tuck, S. (1998). Caenorhabditis elegans lin-25: cellular focus, protein expression and requirement for sur-2 during induction of vulval fates. Development 125 , 4809-4819. Abstract

Podbilewicz, B. (2000). Membrane fusion as a morphogenetic force in nematode development. Nematology 2, 99-111. Article

Podbilewicz, B., and Chernomordik, L.V. (2005). Cell fusion in development and disease. In: Protein-lipids interactions, L.K. Tamm, ed. (New York: Wiley-VCH), pp. 221-224.

Podbilewicz, B., and White, J.G. (1994). Cell fusions in the developing epithelia of C. elegans. Dev. Biol. 161, 408-424. Abstract Article

Priess, J.R., and Hirsh, D.I. (1986). Caenorhabditis elegans morphogenesis: The role of cytoskeleton in elongation of the embryo. Dev. Biol. 117, 156-173. Abstract Article

Primakoff, P., and Myles, D.G. (2002). Penetration, adhesion, and fusion in mammalian sperm-egg interaction. Science 296, 2183-2185. Abstract Article

Rabin, Y., and Podbilewicz, B. (2000). Temperature-controlled microscopy for imaging living cells: apparatus, thermal analysis, and temperature dependency of embryonic elongation in C. elegans. J Microsc 199 ( Pt 3), 214-223. Abstract Article

Reinhart, B.J., Slack, F.J., Basson, M., Pasquinelli, A.E., Bettinger, J.C., Rougvie, A.E., Horvitz, H.R., and Ruvkun, G. (2000). The 21-nucleotide let-7 RNA regulates developmental timing in Caenorhabditis elegans. Nature 403, 901-906. Abstract Article 
Rougvie, A.E., and Ambros, V. (1995). The heterochronic gene lin-29 encodes a zinc finger protein that controls a terminal differentiation event in Caenorhabditis elegans. Development 121, 2491-2500. Abstract

Salser, S.J., and Kenyon, C. (1994). Patterning C. elegans: homeotic cluster genes, cell fates and cell migrations. Trends Genet. 10, 159-164. Abstract Article

Salser, S.J., Loer, C.M., and Kenyon, C. (1993). Multiple HOM-C gene interactions specify cell fates in the nematode central nervous system. Genes Dev. 7, 1714-1724. Abstract

Schierenberg, E. (1984). Altered cell-division rates after laser-induced cell fusion in nematode embryos. Dev. Biol. 101, 240-245. Abstract Article

Schierenberg, E. (1987). Laser-induced cell fusion. In Cell Fusion, A.E. Sowers, ed. (Plenum Press), pp. 409-418.

Sharma-Kishore, R., White, J.G., Southgate, E., and Podbilewicz, B. (1999). Formation of the vulva in C. elegans: a paradigm for organogenesis. Development 126, 691-699. Abstract

Shemer, G. (2002) Cell fusion and organogenesis in Caenorhabditis elegans, Ph. D., Technion - Israel Institute for Technology, Haifa.

Shemer, G., Kishore, R., and Podbilewicz, B. (2000). Ring formation drives invagination of the vulva in C. elegans: Ras, cell fusion and cell migration determine structural fates. Dev. Biol. 221, 233-248. Abstract Article

Shemer, G., and Podbilewicz, B. (2000). Fusomorphogenesis: Cell fusion in organ formation. Dev. Dyn. 218, 30-51. Abstract Article

Shemer, G., and Podbilewicz, B. (2002). LIN-39/Hox triggers cell division and represses EFF-1/Fusogen-dependent vulval cell fusion. Genes Dev. 16, 3136-3141. Abstract Article

Shemer, G., and Podbilewicz, B. (2003). The story of cell fusion: big lessons from little worms. Bioessays 25, 672-682. Abstract Article

Shemer, G., Suissa, M., Kolotuev, I., Nguyen, K.C.Q., Hall, D.H., and Podbilewicz, B. (2004). EFF-1 is sufficient to initiate and execute tissue-specific cell fusion in C. elegans. Curr. Biol. 14, 1587-1591. Abstract Article

Shur, B.D., Ensslin, M.A., and Rodeheffer, C. (2004). SED1 function during mammalian sperm-egg adhesion. Curr. Opin. Cell Biol. 16, 477-485. Abstract Article

Silhankova, M., Jindra, M., and Asahina, M. (2005). Nuclear receptor NHR-25 is required for cell-shape dynamics during epidermal differentiation in Caenorhabditis elegans. J. Cell Sci. 118, 223-232. Abstract Article

Simske, J.S., and Hardin, J. (2001). Getting into shape: epidermal morphogenesis in Caenorhabditis elegans embryos. Bioessays 23, 12-23. Abstract Article

Singh, R.N., and Sulston, J.E. (1978). Some observations on moulting in Caenorhabditis elegans. Nematologica 24, 63-71.

Singson, A. (2001). Every sperm is sacred: fertilization in Caenorhabditis elegans. Dev. Biol. 230, 101-109. Abstract Article

Singson, A., Mercer, K.B., and L'Hernault, S.W. (1998). The C. elegans spe-9 gene encodes a sperm transmembrane protein that contains egf-like repeats and is required for fertilization. Cell 93, 71-79. Abstract Article

Slack, F., and Ruvkun, G. (1997). Temporal pattern formation by heterochronic genes. Ann. Rev. Genet. 31, 611-634. Abstract Article

Solari, F., and Ahringer, J. (2000). NURD-complex genes antagonise Ras-induced vulval development in Caenorhabditis elegans. Curr. Biol. 10, 223-226. Abstract Article 
Solari, F., Bateman, A., and Ahringer, J. (1999). The Caenorhabditis elegansgenes egl-27 and egr-1are similar to MTA1, a member of a chromatin regulatory compex, and are redundantly required for enbryonic patterning. Development 126, 2483-2494. Abstract

Stein, K.K., Primakoff, P., and Myles, D. (2004). Sperm-egg fusion: events at the plasma membrane. J. Cell Sci. 117, 6269-6274. Abstract Article

Sulston, J.E., and Horvitz, H.R. (1977). Postembryonic cell lineages of the nematode Caenorhabditis elegans. Dev. Biol. 56, 110-156. Abstract Article

Sulston, J.E., Schierenberg, E., White, J.G., and Thomson, J.N. (1983). The Embryonic Cell Lineage of the Nematode Caenorhabditis elegans. Dev. Biol. 100, 64-119. Abstract Article

Terada, N., Hamazaki, T., Oka, M., Hoki, M., Mastalerz, D.M., Nakano, Y., Meyer, E.M., Morel, L., Petersen, B.E., and Scott, E.W. (2002). Bone marrow cells adopt the phenotype of other cells by spontaneous cell fusion. Nature 416, 542-545. Abstract Article

Terns, R.M., Kroll-Conner, P., Zhu, J., Chung, S., and Rothman, J.H. (1997). A deficiency screen for zygotic loci required for establishment and patterning of the epidermis in Caenorhabidtis elegans. Genetics 146, $185-206$. Abstract

Thomas, J.H., Ceol, C.J., Schwartz, H.T., and Horvitz, H.R. (2003). New genes that interact with lin-35 Rb to negatively regulate the let-60 ras pathway in Caenorhabditis elegans. Genetics 164, 135-151. Abstract

Trueheart, J., and Fink, G.R. (1989). The yeast cell fusion protein FUS1 is O-glycosylated and spans the plasma membrane. Proc. Natl. Acad. Sci. USA 86, 9916-9920. Abstract

Van Auken, K., Weaver, D.C., Edgar, L.G., and Wood, W.B. (2000). Caenorhabditis elegans embryonic axial patterning requires two recently discovered posterior-group Hox genes. Proc. Natl. Acad. Sci. USA 97, 4499-4503. Abstract Article

von Zelewsky, T., Palladino, F., Brunschwig, K., Tobler, H., Hajnal, A., and Muller, F. (2000). The C. elegans Mi-2 chromatin-remodelling proteins function in vulval cell fate determination. Development 127, 5277-5284. Abstract

Wang, B.B., Muller-Immergluck, M.M., Austin, J., Robinson, N.T., Chisholm, A., and Kenyon, C. (1993). A homeotic gene cluster patterns the anteroposterior body axis of C. elegans. Cell 74, 29-42. Abstract Article

Wang, M., and Sternberg, P.W. (2001). Pattern formation during C. elegans vulval induction. Curr. Top. Dev. Biol. 51, 189-220. Abstract

Wassarman, P.M., Jovine, L., and Litscher, E.S. (2001). A profile of fertilization in mammals. Nat. Cell Biol. 3, E59-E64. Abstract Article

White, J.G. (1988). The Anatomy. In The Nematode Caenorhabditis elegans, W.B. Wood, ed. (Cold Spring Harbor, Cold Spring Harbor Laboratory), pp. 81-122. Abstract Article

Wittmann, C., Bossinger, O., Goldstein, B., Fleischmann, M., Kohler, R., Brunschwig, K., Tobler, H., and Muller, F. (1997). The expression of the C. elegans labial-like Hox gene ceh-13 during early embryogenesis relies on cell fate and on anteroposterior cell polarity. Development 124, 4193-4200. Abstract

Witze, E., and Rothman, J.H. (2002). Cell Fusion: an efficient sculptor. Curr. Biol. 12, R467-R469. Article

Xiang, Q., Rasmussen, C., and Glass, N.L. (2002). The ham-2 locus, encoding a putative transmembrane protein, is required for hyphal fusion in Neurospora crassa. Genetics 160, 169-180. Abstract

Xu, X.Z., and Sternberg, P.W. (2003). A C. elegans sperm TRP protein required for sperm-egg interactions during fertilization. Cell 114, 285-297. Abstract Article

Ying, Q.L., Nichols, J., Evans, E.P., and Smith, A.G. (2002). Changing potency by spontaneous fusion. Nature 416, 545-548. Abstract Article 
Yochem, J., Gu, T., and Han, M. (1998). A new marker for mosaic analysis in Caenorhabditis elegans indicates a fusion between hyp6 and hyp7, two major components of the hypodermis. Genetics 149, 1323-1334. Abstract

Zhao, X., Yang, Y., Fitch, D.A., and Herman, M.E. (2002). TLP-1 is an asymmetric cell fate determinant that responds to Wnt signals and controls male tail tip morphogenesis. Development 129, 1497-1508. Abstract

All WormBook content, except where otherwise noted, is licensed under a Creative 